\title{
Simulation and impact analysis of behavioral and socioeconomic dimensions of energy consumption
}

\author{
Ali Ghofrani ${ }^{a}$, Esmat Zaidan ${ }^{\text {a, }}$,, Ammar Abulibdeh ${ }^{\mathrm{b}}$ \\ a Policy, Planning, and Development Program, Department of International Affairs, College of Arts and Sciences, Qatar University, Doha, Qatar \\ ${ }^{\mathrm{b}}$ Applied Geography and GIS program, Department of Humanities, College of Arts and Sciences, Qatar University, Doha, Qatar
}

\section{A R T I C L E I N F O}

Article history:

Received 12 December 2020

Received in revised form

3 October 2021

Accepted 30 October 2021

Available online $\mathrm{xxx}$

\section{Keywords:}

Energy policy

Residential buildings

Socioeconomics

Human behavior

Simulation

Machine learning

\begin{abstract}
A B S T R A C T
Human-oriented factors present unavoidable challenges and uncertainties in building energy strategic planning. The uncertainties escalate when the target society is not fully known to the decision-maker and can create performance gaps between the expected and actual outcomes of sustainability targets. This article aims to investigate the role of socioeconomic and behavioral dimensions in residential energy consumption patterns among regions that host high proportions of migrant communities with diverse cultural and ethnic traits. This study evaluates the patterns in human-building interactions and energy behaviors among local and migrant communities based on empirical evidence and survey analysis. The survey data are investigated via machine learning approaches to identify the interdependencies between and feature importance of critical factors that influence human-building interactions and to determine elements that help to discern the energy behavior of locals and migrants. A simulation analysis is conducted to analyze residential energy consumption under different human indoor thermal comfort preferences in multiple case scenarios to demonstrate how improvements in human-building interaction can create saving opportunities. The findings capture the main socioeconomic and behavioral contributors in residential energy consumption and demonstrate the impact of human factor at a high level in regions with imbalanced demographics and societies in transition.
\end{abstract}

() 2021 Elsevier Ltd. All rights reserved.

\section{Introduction}

Built environments can be considered as one of the primary contributors to the energy sector [1]. At the same time, the immense role of human dimensions in built environments and energy consumption cannot be ignored. As a result, buildings and human factors can have a significant impact on energy decisionmaking and the energy transition as the critical drivers of both [2]. Investigating the critical drivers of energy consumption has always been an important subject due to the impact of the energy sector on the economy, environment, and society [3]. Worldwide, energy policies are increasingly being oriented towards sustainable development goals and challenges associated with the rapid growth of urbanization and industrialization [4]. However, most of the current practices in sustainable development and energy transition are focused mainly on technical aspects, feasibility studies, and economic dimensions, and the human factor and the

\footnotetext{
* Corresponding author.

E-mail address: ezaidan@qu.edu.qa (E. Zaidan).
}

social dimensions are yet to either influence decision-making or be incorporated in holistic energy policies. Social science scholars have always criticized the dominant energy conservation studies due to the lack of complex social aspects [5]. Although, mainly adding short-term insight in energy policy, the role of social and demographic factors, along with their interdependencies, need to be incorporated effectively as part of interdisciplinary practice in energy transition [6]. In this regard, different stages of human action phases (pre-decision, pre-action, action, and post-action) and behavioral factors can be categorized, understood, and integrated into energy transition targets [7]. These behavioral factors can be social norms, personal norms, emotions, attitude, trust, skills, etc., each of which can affect high-level decision-making when individuals' behavior in a society is aggregated and considered at macroscales. Macroscale human behavior attributed to energy consumption patterns can also influence energy policy and, consequently, economic and environmental dimensions [8].

Although the role of social sciences is crucial, integrating such elements in the energy transition is challenging and requires further effort. Stern [8] demonstrates current research challenges 
and differentiates between pure and applied Social Science Energy Research (SSER). Stern [9] also categorizes research topics influencing the field into a non-measurable/non-physical point of view (e.g., global agreements associated with energy and climate, energy development impact on society, and impacts of political and economic factors) and a measurable physical point of view (e.g., solutions for emission reduction in households). There are comprehensive studies focusing on pure SSER, applied SSER, and a combination of both approaches in the literature to investigate the interconnection between human factor and technical-economic elements and to find solutions in energy conservation.

The implications of human behavior are highly stochastic, casespecific, and a posteriori knowledge [10], meaning that valid conclusions must be drawn through empirical evidence [11]. Rinaldi et al. outlined how influencing human dimensions can be gleaned by means of surveys and empirical analysis [12]. Such analysis concerning human dimensions and built environments is well established in the literature and covers a wide spectrum of categories, specifically demographic and socioeconomic factors. Bhattacharjee et al. [13] found correlations between residential energy consumption and consumer attitude, along with demographics, economy, and climate that can, in turn, be attributed to intervention strategies. Authors in Ref. [14] reported the intercorrelations of households age-compositions and education level with residential energy use patterns. The influence of human factors, including, socioeconomic and human attitude, on energy use patterns can be seen in Ref. [15], where associations were reported between the users' willingness towards home energy saving and possible consequences on their indoor comfort. Koupaei et al. [16] demonstrated users' motivations behind using smart thermostats as thermal comfort rather than financial goals. As seen in these studies, an empirical analysis based on demographic and socioeconomic factors can become significantly case-specific with various permutations between human dimensions and topics in residential energy use. However, the analysis of human-building factors seems to be more generic and applicable to wider perspectives when it comes to behavioral factors and psychological traits.

Li et al. [17] used three different characteristics (motivation, opportunity, and ability) for consumer segmentation to find different energy use behaviors in buildings and their response to control interventions through a statistical approach and based on multiple hypothesis tests. Adua [18] identified physical-technical-economic practices and social behavior/lifestyle elements as the main elements in energy use patterns. Moezzi and Janda [19] identified energy interventions associated with monetary savings and global good contributions by investigating factors such as individual choice, information, and the transformation of morals in building energy efficiency. As described in Ref. [17], aside from human motivations, opportunity and ability are also significant energy efficiency factors that can be attributed to building environment and technology, such as automated systems and building envelopes. Such building capabilities can establish better directions of human behavior and also reduce consumption via improved building operation, infiltration, or heat loss reduction [20]. It is reported that raising awareness among residential endusers and improving behavioral factors through non-monetary intervention strategies have a potential saving up to $20 \%$, and, successful behavioral campaigns can achieve $2 \%$ total energy savings in the residential sector [21]. However, in order to incorporate the role of human-driven factors in residential energy policy and strategic planning, the challenges, means, and efficacies must be fully investigated.

Jensen et al. [22] developed a framework to classify different initiatives in Europe and investigate challenges and the role of social factors from individual consumers to societies impacting energy use and the effectiveness of these energy and climate policies. Ohnmacht et al. [23] placed greater emphasis on individual consumer behavior and the linkage between socio-psychological factors and interventions. They developed a roadmap for a transition between behavioral phases based on socio-psychological factors and environmental contexts to determine how to establish new habitual behaviors (attributed to energy) as a post-action phase initiated from goal intention. Besides sociopsychological factors, the intervention strategies to shape targets and behavioral change techniques are categorized as positive motivational, coercive, and incentives in Ref. [24]. The application of such practices can be observed in government tax rebates, incentives, penalties, education, feedback, and training across the world [25]. The impact of the factors mentioned above has been assessed comprehensively and implemented in energy market design and energy policy for different demographics and societies [26]. The applications cover a broad range, including new technologies, distributed energy resources, storage systems, and electrification for individuals and communities [27].

However, implementing and assessing theoretical energy efficiency or policy strategies are likely to result in performance gaps between the actual and the expected outcomes. Gerarden et al. $[28,29]$ classify energy efficiency gaps as being between what is technologically and financially feasible and the measures perceived by individuals. These gaps can be categorized as market challenges, pricing underestimation, and behavioral challenges. The energy policy performance gap becomes larger when there is more uncertainty and complexity in social factors, demographics, and the economy. Therefore, empirical evidence for the efficacy of energy decision-making is required to validate the theoretical assumptions and achieve strategic goals. This is especially the case for societies in transition, such as Gulf Cooperation Council countries (GCC), with dynamic socioeconomic and urbanization development that host large proportions of expatriate communities that vary from $30 \%$ to $90 \%$ of their total population $[30,31]$. The expatriate communities exhibit a wide variety of psychological, cultural, and ethnic traits, which create discrepancies between the local/foreign communities and escalate the human-driven complexities in energy decision-making. The aforementioned discrepancies are noticeable in factors, such as human-building interactions (HBI), attitude, social norms, normative goals, gain goals, and perceived responsibility factors [11], which in turn, can influence the outcome of building sector strategies. Further, the inclusion of human dimensions in building energy policy and discerning the energy behavior of local and foreign communities is critical in developing countries due to the economic challenges the governments are facing with regard to energy subsidies that primarily benefit the residents [32]. To this end, reshaping building energy policy based on the assessment of human drivers can offer a new set of alternatives to pursue sustainability goals. Given the diversified economy and the growing energy demand of GCC countries [33], even slight enhancements could dramatically bolster the governments' sustainability efforts.

The role of human-driven complexities in transient societies is still in need of empirical analysis and comprehensive investigations due to their rapid economic and demographic transition in the recent years. Besides, there is a lack in the literature concerning the discrepancies between migrant communities and local communities concerning behavioral dimensions in building energy sector. This study combines pure and applied social science energy research to identify the main human behavior drivers in residential energy consumption and find potential energy-saving and emission reduction solutions in Qatar, as a GCC founder, based on an empirical and simulation analysis. Doha is the subject of this study, 
as there have been several concerns about evaluating whether the sustainable energy policies of Qatar, as a fast-growing economy, will achieve desirable transitions [34]. On the other hand, Qatari citizens, unlike non-citizen residents, benefit from energy subsidies that add more complexity to the social dimension in energy policy strategies [35]. This study is the first survey study to assess behavioral and socioeconomic dimensions in residential energy consumption in Qatar, using a sample of more than 3200 households. The case study is unique and informative due to Qatar's demography and energy policies that contain a variety of information to facilitate understanding of the critical factors in energy policy of the region. The survey data are evaluated to find the discrepancies in energy attitude of Qatari citizens and non-citizen communities. This insight is then attributed to indirect inferences such as correlations between demographic traits and personal responsibility norms or the associations between energy subsidies and energy behavior. We propose a statistical analysis where the aim is to model the current electricity consumption behavior and determine the significant factors that affect this behavior among Qataris and Non-Qataries. In addition, a feature importance analysis via random forest method is conducted to find factors that contribute most to residential energy consumption and factors that help to discern citizens and non-citizens based on their energy behavior traits. The survey data are deployed in a simulation analysis to demonstrate how improving HBIs and establishing new behavioral norms in indoor thermal preference, as the main contributor to residential electricity consumption in the region, can lead into noticeable energy saving potentials at an aggregate level. The outcomes are then elaborated and discussed comprehensively to demonstrate how human-oriented strategies must be targeted to close the energy policy performance gaps. The paper is organized as follows: the problem statement description, the survey structure, the survey analysis to find significant factors in residential energy consumption, simulations to find saving potential, discussions, and conclusions.

\section{Problem statement}

\subsection{Motivations}

Energy policymaking in Qatar is challenging due to the country's climate, unique demography, and fast-growing energy demand [36]. Besides a uniform and arid climate that creates high cooling demands [37], Qatar has a unique demography, with a population consisting of $88 \%$ non-citizen residents and $12 \%$ Qatari citizens with specific energy incentives and subsidies. Indeed, figures show that Qatar has spent about $\$ 46,000$ per Qatari citizen on desalinated water and power production over the last decade [38]. Non-Qatari must pay a combined electricity and water bill on monthly basis. This is indicative of the vital role of the human factor in energy policy that can make conventional energy policy practices be less effective and less viable in Qatar. Conventional economic-based strategies and incentives for energy efficiency in Qatar are not expected to be fully effective due to the existing energy subsidies and high per capita income, especially in the residential sector [39]. The residential sector in Qatar is the largest consumer of energy, accounting for more than $40 \%$ of the total consumption. Thus, residential energy consumption patterns have become an essential target for the electric power industry in Qatar to identify energy conservation opportunities. Fig. 1 illustrates the breakdown of Qatar's electricity consumption by sector in 2011 [40].

As mentioned above, Qatar's arid climate makes energy decision-making even more challenging. To show the impact of the hot weather conditions on Qatar's residential electricity demand, we constructed a building simulation using EnergyPlus software
[41] for a single-family house with a total area of $200 \mathrm{~m}^{2}$ and according to The American Society of Heating, Refrigerating and AirConditioning Engineers (ASHRAE) 189.1 and 90.1 standards [42] and climate zone $1 \mathrm{~B}$ assumptions (very hot and dry climate). We note that Standard 189.1 provides total building sustainability guidance for designing, building, and operating high-performance green buildings. Standard 90.1 provides minimum requirements for energy efficient designs for buildings except for low-rise residential buildings. As most of Qatar population are expatriates and the majority live in apartments, we set in our simulation the house area equal to $200 \mathrm{~m}^{2}$. The geometry of the building simulation is shown in Fig. 2, where the model is based on a ducted packaged air conditioner with DX cooling coil, uncontrolled single-duct air terminals, constant supply fan, a window to wall ratio of 0.4 , and the distribution of weather conditions on hour-basis for 1 year, shown in Fig. 3 (based on Typical Meteorological Year 2 (TMY2) [43]). Fig. 4 illustrates the breakdown of the electricity consumption of the representative building.

The results are indicative of the fact that cooling demand is highly dominant in electricity consumption in arid areas. A sensitivity analysis between two different scenarios indicates that changing the cooling setpoint temperature from $21^{\circ} \mathrm{C}$ to $24^{\circ} \mathrm{C}$ will result in an $18.7 \%$ saving in total annual electricity consumption and an $11.6 \%$ peak demand reduction, which is a noticeable change (Fig. 5). Hence, since AC systems are controllable loads and highly reliant on human choice and interactions, this end-use can offer promising saving potentials concerning human drivers. This improvement is noticeable but not particularly viable due to consumers' attitudes, gain goals, normative goals, habits, thermal perceptions, and indoor environment preferences. It should be noted that improving cooling consumption based on human drivers cannot be limited to the above HBI factors. For instance, consumers' tendency to adopt energy efficiency solutions or willingness toward participating in demand response programs are among humandriven factors that offer additional energy saving potentials. The objective in this situation is to identify the associations between demographic/ethnic traits of segments of society and the factors that contribute most to energy behavior changes, and as mentioned previously, it is expected to observe discrepancies between the local and expatriate communities in societies similar to GCC countries.

To this end, two main elements are emphasized and applied on multiple case scenarios based on an empirical analysis in Doha, Qatar:

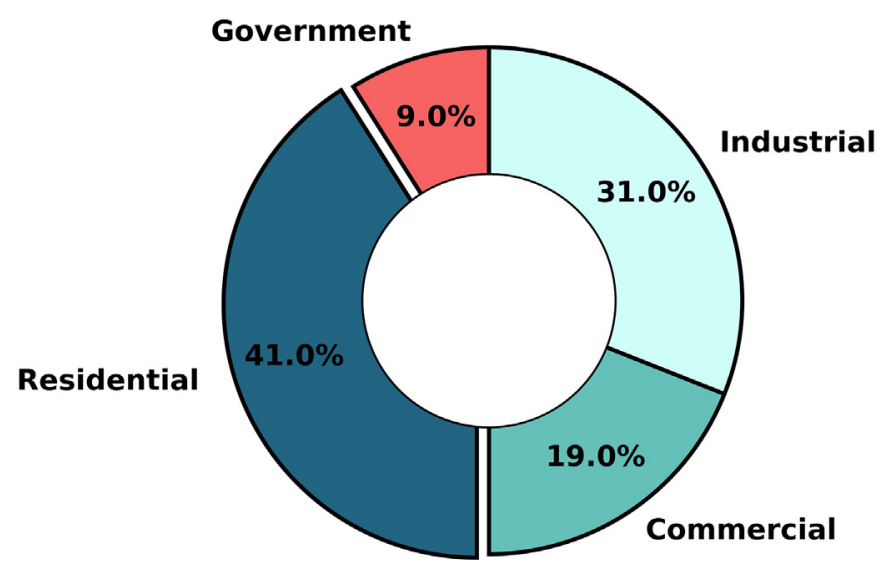

Fig. 1. Qatar electricity consumption by sector in 2011. 

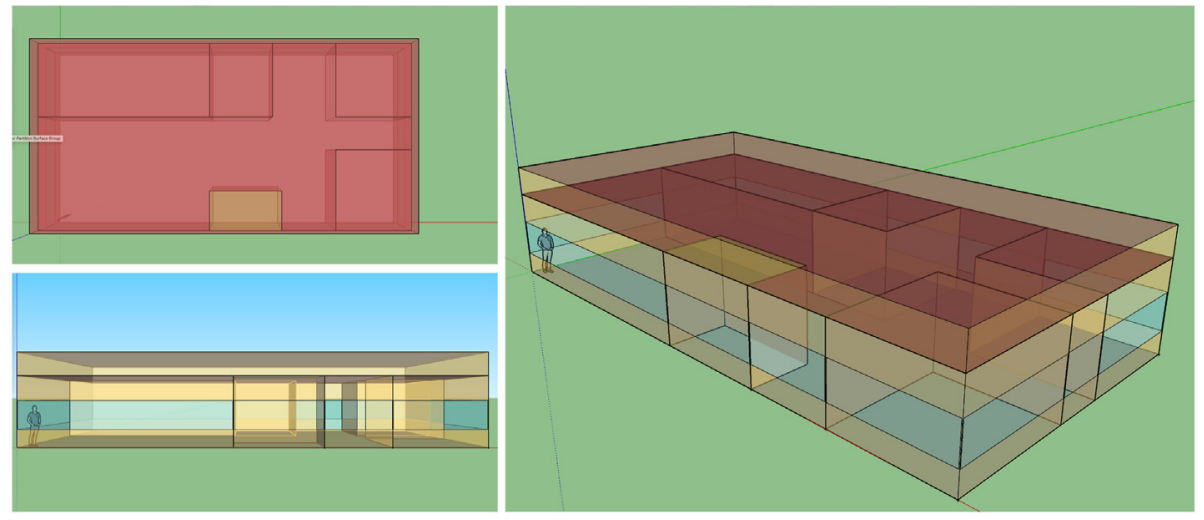

Fig. 2. Different views of the building simulation of a single-family house representing a residential building in Doha, Qatar.
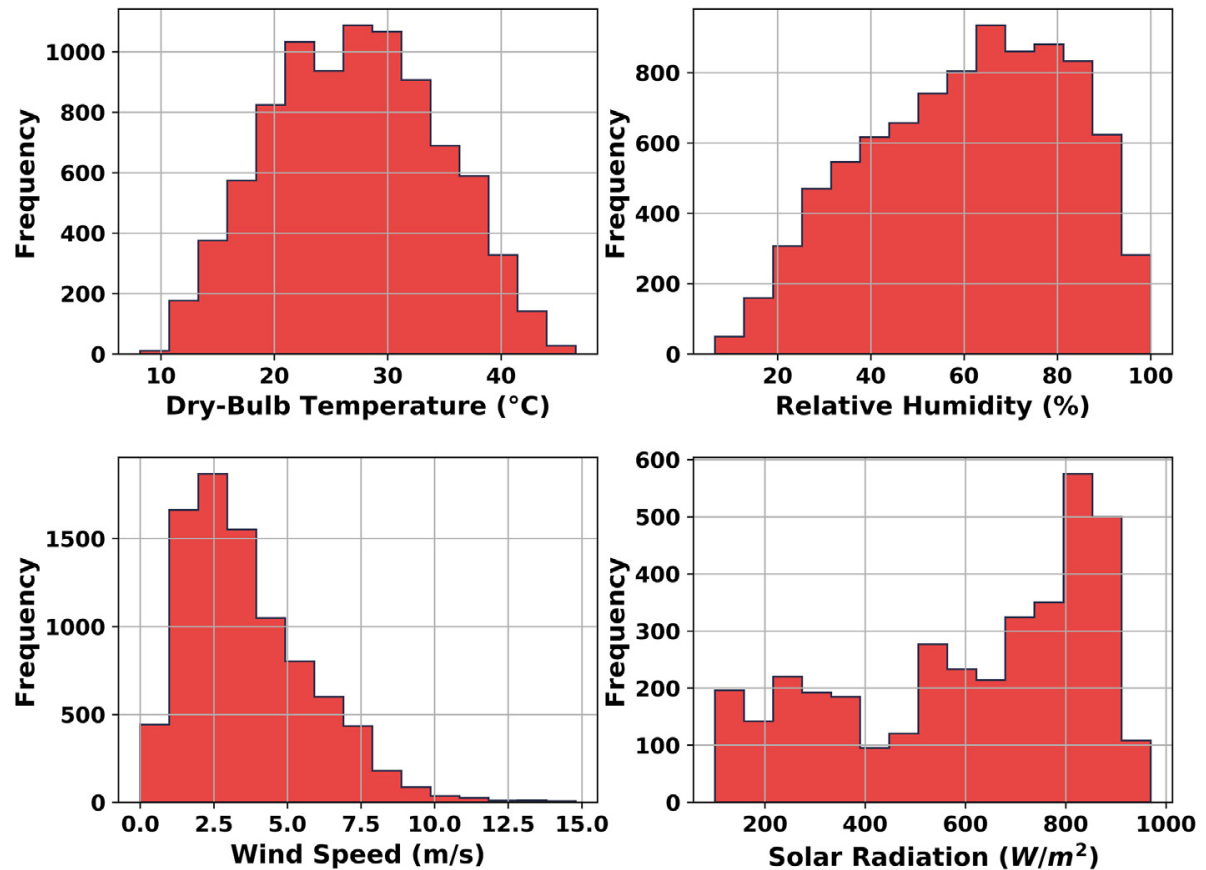

Fig. 3. Distribution of the annual weather condition in Doha, Qatar, used in the building simulation based on TMY2 database [44].

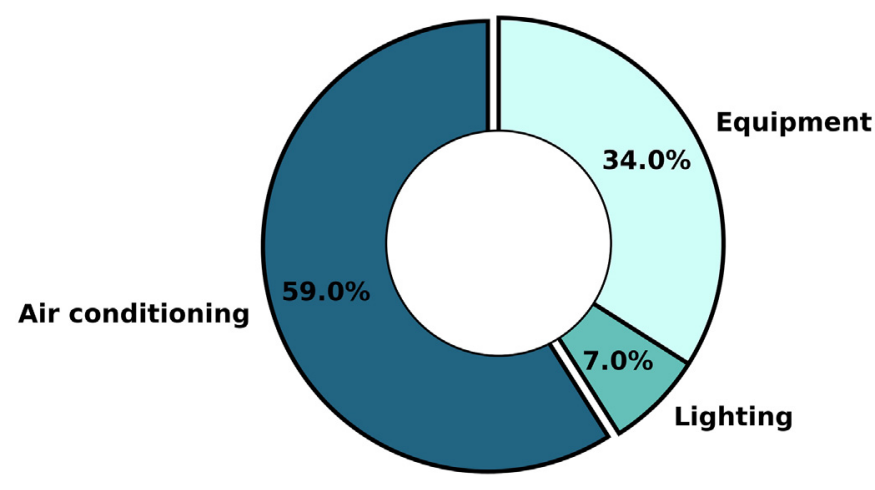

Fig. 4. Building electricity consumption by end use based on an EnergyPlus simulation for a single-family house in Qatar.

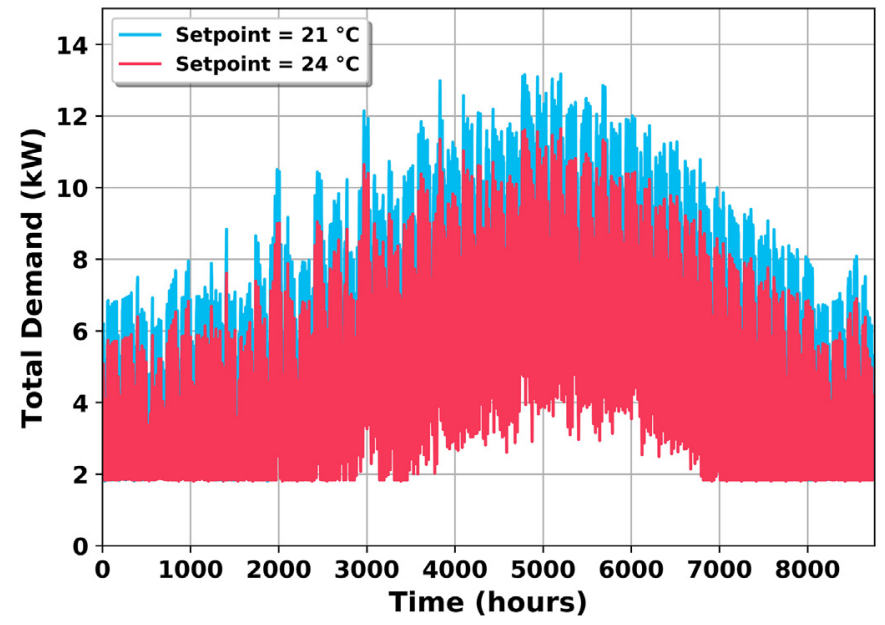

Fig. 5. The impact of temperature setpoint change on building electricity demand over a one-year period $(8760 \mathrm{~h})$. 
- Evaluating socioeconomic and behavioral factors in diverse demographic communities to be integrated in energy policy and addressing gaps and challenges associated with human factors in residential energy use in Qatar and countries with transient demographics and energy policies.

- Demonstrating the impact of human-building interactions on residential energy consumption and identifying energy conservation potentials associated with establishing habitual new norms in human's indoor thermal comfort choice, as a quantifiable and crucial HBI factor.

\subsection{Methodology}

This study, illustrated in Fig. 6, deploys a combined empirical and simulation analysis to evaluate the patterns in human energy behavior among local and migrant communities in Qatar. The empirical analysis is based on a sample that represents a variety of demographic, socioeconomic, and behavioral factors. The sampling process is followed by imputation methods and data preprocessing, such as multivariate feature imputation [45], for the missing data to maintain the useful information in the whole sample. These techniques include filling the missing values with zeros, the feature median values across all samples and the multivariate feature imputation. Afterwards, the observed human-dimension factors are qualitatively investigated to compare the discrepancies between citizen and non-citizen communities with respect to traits, such as consequence awareness, attitude toward energy efficiency and building retrofit investment, along with self-perceived building interactions with cooling system, lighting system, and appliances. The discrepancies are then interpreted to find any associations between citizenship status and crucial aspects, including sense of responsibility and consumption patterns, especially considering the important facts that the majority of the expatriates are not permanent residents and Qataris are benefited from energy subsidies. Next, a statistical analysis is conducted to determine how significance of the behavioral impact on both communities. Then, a feature importance analysis based on random forest classification is conducted to determine the key features that contribute most to classifying citizens and non-citizens with respect to the behavioral factors. Besides, the analysis is repeated to find the significant features in human consumption patterns. Afterwards, k-means clustering method is utilized to find groups of respondents with similar attitudes and energy behavior traits. This set of analysis can assist the decision-maker to develop targeted policies, such as incentive modeling, energy pricing, energy awareness programs, and improving HBI norms and prior habits, with more attention to human drivers. HBI interactions with indoor thermal environment, as tangible and quantifiable measures, are selected afterwards to evaluate potential performance improvements by targeting human energy behavior in built environments.

To conduct an impact assessment on creating new norms and choices in HBI, specifically in indoor thermal environment, the available information on the respondents' home features and thermal preference are used in a simulation analysis. Multiple building simulations are created via EnergyPlus software [41] for different building sizes and residential types to model the impact of indoor thermal condition variations on building total electricity consumption. Afterwards, a regression analysis is conducted to generalize the simulation results to various ranges of building sizes and indoor thermal conditions. The self-perceived human building interactions and reported residential building features in the survey are then used to estimate the annual electricity consumption of the sample. Via different scenarios, the impact of improving adverse human preference and prior habits concerning indoor environment is estimated and the energy saving potentials are presented. Finally, distribution functions, via Kernel density estimation, are fitted to the sample's reported building features and indoor thermal preference and the results are extended to the population (Doha municipality) to show an estimated performance improvement as a result of human behavior enhancements at an aggregate level. The savings are discussed and indirect benefits, such as emission reduction, are presented.

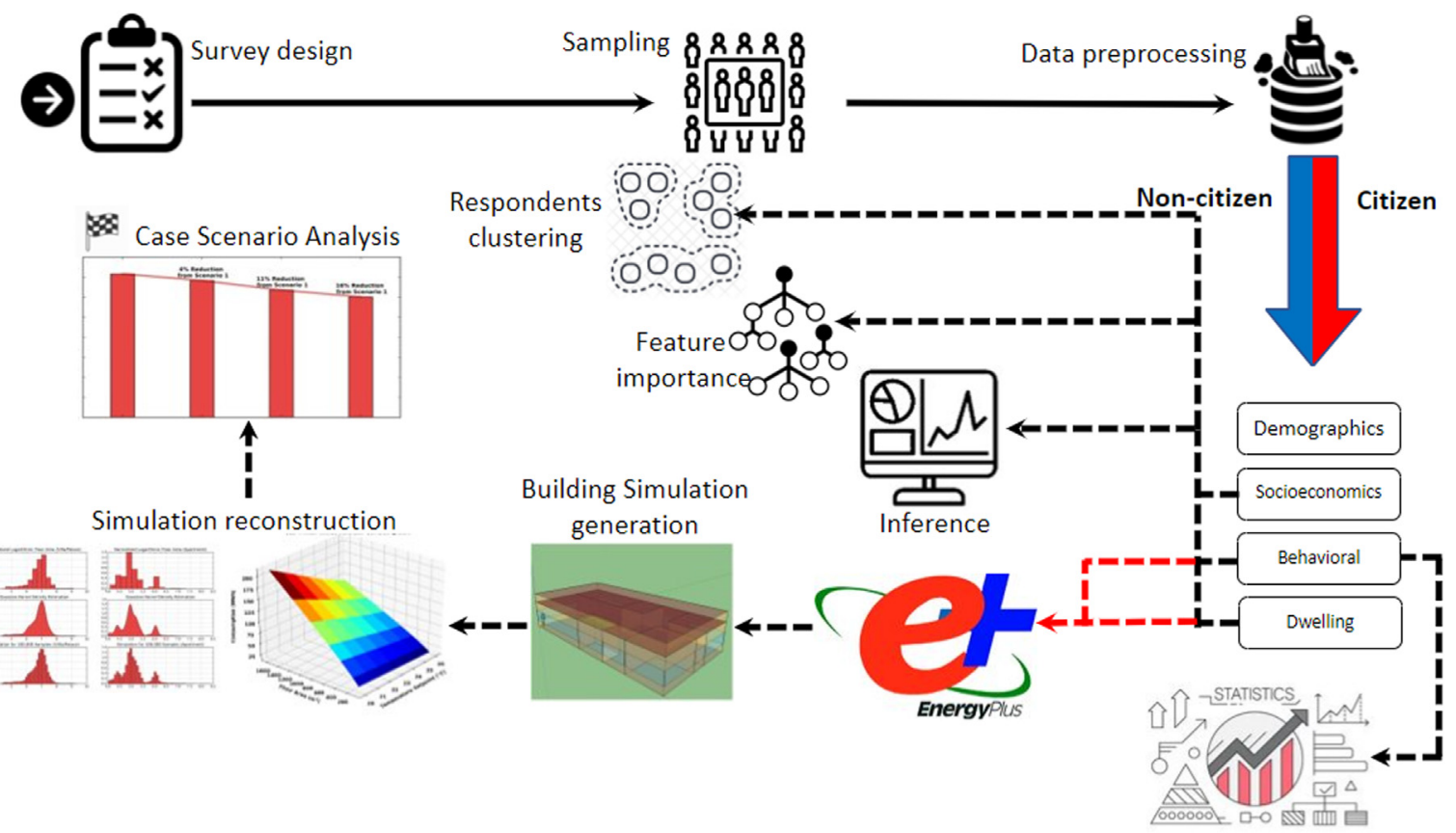

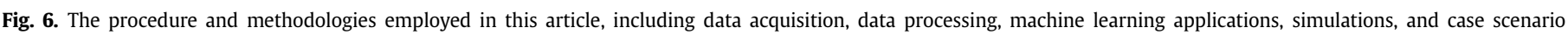
analysis. 


\subsection{Survey framework}

A sample of 3200 households in Doha, Qatar, was targeted to conduct a user survey to understand the interdependencies and discrepancies of human and technical factors in residential buildings among the local and expatiate communities and determine behavioral notions within the sample. The survey was designed to capture three main measures - a) building characteristics, b) socioeconomic factors, and c) behavioral factors - to better understand the distribution of the data, such as demographic information, household attributes, building features, consumer's awareness, consumption attitude, HBIs, and motivations. The survey was also designed to determine gain goals and normative goals in behavioral dimensions.

One of the targets of the survey study was to acquire insight into human consumption habits and human-building interactions behavioral factors. Therefore, indoor temperature preference, indoor lighting preference, and appliance use were selected as measures to evaluate possible demographic and ethnic discrepancies in HBIs. The indoor temperature preference was categorized into cold for temperatures lower than $22{ }^{\circ} \mathrm{C}$, moderate for temperatures between $22{ }^{\circ} \mathrm{C}$ and $24{ }^{\circ} \mathrm{C}$, and hot for temperatures higher than $24^{\circ} \mathrm{C}$. Preferred indoor lighting was composed of dark, moderate, and light preference, and appliance use habits were broken down into rare, moderate, and very often. To better understand the human attitudes and pre-action behavioral factors, subjects were asked about their concern about climate change as a measure for perceived responsibility and normative goals. The subjects' willingness and motivation concerning upgrades and building retrofits for cost and energy saving were regarded as a measure to understand extrinsic motivational factors better. The element was broken down into economic motivation as a gain goal, and environmental/social motivations as normative goals, and perceived responsibility. Lastly, an approximate monthly energy bill was incorporated in the survey as a primary target variable in behavioral factors.

As one of the significant dimensions interacting with residential energy consumption, socioeconomic factors were embedded in the survey study. Demographics factors such as nationality, age, gender, employment category, level of education, and income level were taken into account to assess the intercorrelation mentioned above. The population was broken down into two target communities: citizens (Qatari nationals) and non-citizens (rest of the nationalities).

One of the main objectives of this survey was to find energysaving opportunities by creating new energy consumption habits. Therefore, the general characteristics of the buildings were collected to shape an overall estimation of the sample. These characteristics also help in constructing building simulations and performing sensitivity analysis evaluation if behavioral changes enter the actional phase. The main elements selected to estimate building consumption were home type, floor area, and indoor temperature setpoint.

This study is centered around a representative sample of the target population. To avoid biased findings, one of the major challenges was to avoid concentrating on specific regions or communities for data sampling. Due to budgetary and legal constraints, this objective was not completely fulfilled. Furthermore, the collected information reflects the perceived knowledge of the subjects and how their attitudes toward energy conservation and behavior. Hence the findings validation of self-reported responses is highly contingent on the self-perception of the subjects. Finally, the presence of missing data was an additional challenge. Out of the 3200 surveyed households, 1960 provided complete information.

\section{Survey statement}

To capture the impact of demographics, our aim was to achieve a sample representative of national diversity. Table 1 shows the make-up of the sample according to nationality. People from Arab countries and Qatar are dominant. The nationalities are categorized into two main groups of Citizen (Qatari national) and Non-Citizen (Other nationalities). The breakdown by nationality is important particularly between Qatari and Non-Qatari. Indeed, both communities have different constraints, interests and concerns. Several services are subsidized for citizens including water and electricity. In addition, Non-Qataris are more economically and financially concerned. Across the State of Qatar, both communities live together in close neighborhoods, residential building or compounds.

Demographic factors such as age, gender, and level of education, along with financial measures (household income and expenses), were categorized and are grouped by citizenship (Qatari citizens and expatriate non-citizens) in Fig. 7. As demonstrated in Fig. 7, the subjects are mainly aged from 29 to 50 , male, and have different education and job category distributions with regard to their nationality.

Perceived behavioral factors are shown in Fig. 8. The results indicate that the energy consumption preferences of Qataris and other nationalities differ. Qatari subjects show a greater inclination toward moderate indoor temperatures, whereas non-Qataris are more inclined toward colder temperatures. Qataris show greater inclination toward moderate indoor lighting, whereas non-Qataris prefer lighter spaces. Non-Qataris report that they have high appliance consumption, whereas Qataris have moderate appliance use. These self-perceived human-building interactions indicate that energy subsidies among the Qatari citizens do not create adverse habits, compared to the noncitizen communities, in building energy consumption. As a pre-decisional factor, perceived behaviors associated with the opinions about the effectiveness of equipment upgrades and building retrofits on energy and cost-saving show more positive opinions among local communities. However, more than $20 \%$ of all targeted samples are not confident about the effectiveness of building upgrades and retrofitting. Based on responses concerning participants' opinions about the motivations for adopting home energy efficiency solutions, Qataris show a greater inclination toward normative goals and perceived responsibility (environmental and social priorities). This can be explained by the fact that they are more driven by the sense of responsibility towards their country, its sustainability and future, whereas non-Qataris are more concerned about gain goals (financial priorities). More than $70 \%$ of both groups demonstrate climate change concerns, whereas approximately $10 \%-20 \%$ of both groups are still uncertain about climate change consequences.

The survey was distributed among different home types, as illustrated in Fig. 9. There were four main types considered: a) single-family houses, b) multi-family houses, c) townhouses, and d) condominiums. The distribution of different building

Table 1

The population sizes of different nationalities in the sample.

\begin{tabular}{lll}
\hline Nationality & Group Size & Sample Proportion \\
\hline Arab & 1445 & $45.8 \%$ \\
Qatari & 1254 & $39.71 \%$ \\
Asian & 372 & $11.8 \%$ \\
European & 53 & $1.67 \%$ \\
Other & 18 & $0.57 \%$ \\
North American & 13 & $0.41 \%$ \\
Total & 3155 & \\
\hline
\end{tabular}



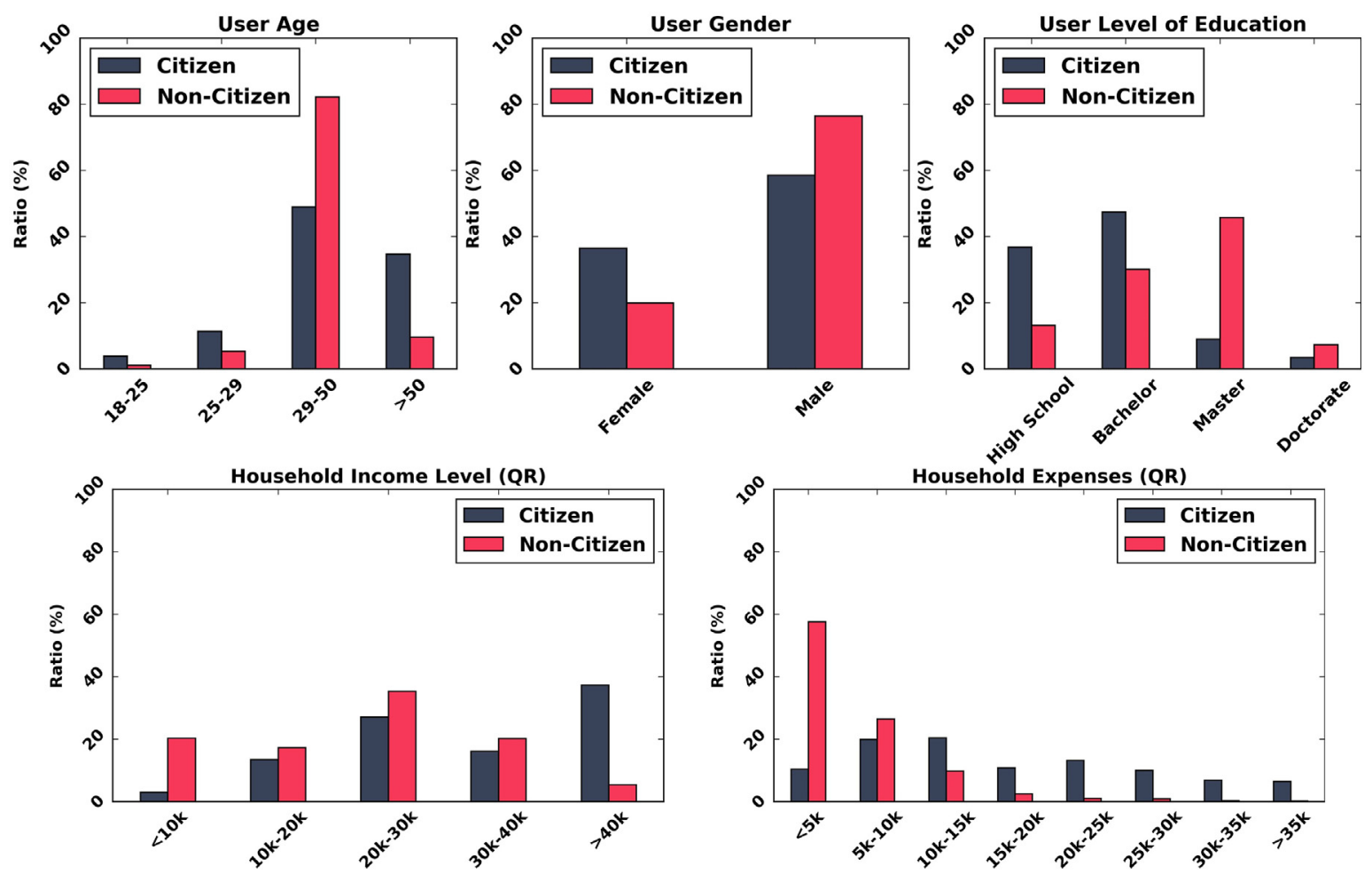

Fig. 7. Demographic and financial factors in the survey results categorized according to Qatari citizens and non-citizens (expatriates).
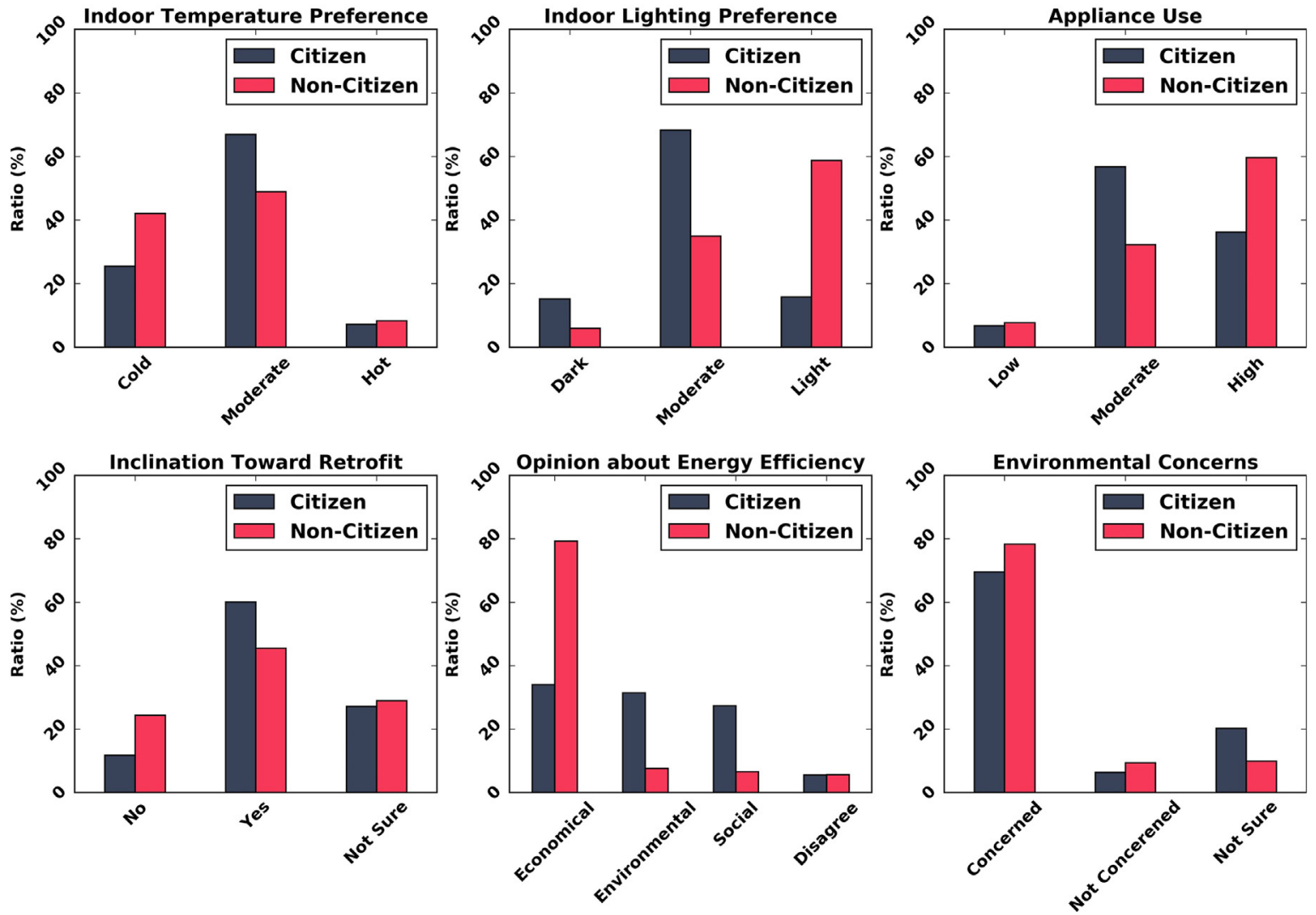

Fig. 8. Perceived behavioral factors based on the survey results. 
characteristics is illustrated in Fig. 10. These inputs are necessary for the simulation, impact analysis, and assessment of saving opportunities resulting from establishing habitual new behaviors associated with HBI and energy use.

As a crucial behavioral factor, the monthly estimated electricity bill (reported by the subjects) is shown in Fig. 11. The ratio represents the percentage of samples whose electricity bill is $<500 \mathrm{QR}$, between 500 and $1000 \mathrm{QR}$, etc, out of the total number of NonQatari samples. It has to be noted that despite the fact that Qataris benefit from an energy subsidy they still receive their monthly electricity bills.

\section{Identification and modeling of behavioral factors}

This section employs analytical approaches to find associations among behavioral factors. A statistical analysis is first conducted. Next, an ensemble learning approach (random forest classifier) was selected to identify the importance of behavioral features with respect to (1) citizenship status and (2) monthly electricity consumption (per area) of the subjects. Via different models, the outcome of the feature importance analysis determines what behavioral factors most contribute to the discrepancies between local and expatriate communities (with citizenship as the target variable) and what features contain insightful information to classify the respondents' monthly electricity consumptions. The endogenous and exogenous variables have been categorized as follows:

- Endogenous variables o Citizenship as a binary variable o Monthly electricity bill per area of the whole sample

- Exogenous variables based on behavioral factors o Climate change consequence attitude

o Motivations for home energy efficiency

o Indoor lighting preference

o Appliance use

o Willingness towards home retrofit and upgrade

o Indoor environment thermal comfort preference

- Exogenous variables based on building features

o Number of household members

o Type of residential building

o Number of bedrooms

o Building floor area

o Building construction year

- Exogenous variables based on demographic and socioeconomic factors

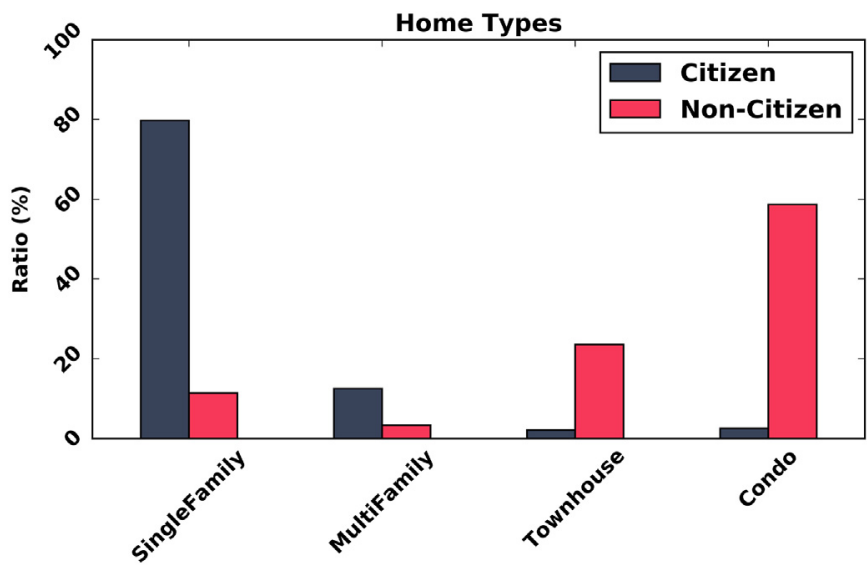

Fig. 9. The distribution of the home types among the sample.
o Gender
o Age
o Nationality
o Education
o Income

In addition, the k-means clustering algorithm has been used to identify similar groups defined by their behavioral features. The outcome of this clustering model would assist the decision-maker to break down the population into segments with the same attitudes and applicable targeted strategy.

\subsection{Modeling current electricity consumption behavior}

A binary logit regression model has been used to analyze the current electricity consumption behavior among end-users and to control for potential determinants, including the behavioral elements shown in Table 3. The model was designed to predict a categorical variable from a set of predictor variables based on the odds ratio between the variables. To compare the electricity consumption behavior among the residents in Qatar, and to determine the factors that might influence electricity consumption, the dependent variable in this model was set to " 0 " for Qataris and to "1" for non-Qataris. The Binary Logistic Model does not assume linearity in the association between the dependent and independent variables [46]. It can predict the possibility of the occurrence of the specific event based on the independent variables. The model can be formulated as expressed in equation (1):

$P_{n 1}=\frac{\exp \left(\beta X_{1 n}\right)}{\exp \left(\beta X_{1 n}\right)+\exp \left(\beta X_{2 n}\right)}=\frac{1}{1+\exp \left(\beta X_{2 n}-\beta X_{1 n}\right)}=\frac{1}{1+\exp (\Delta U)}$

where:

$\mathrm{P}_{\mathrm{n} 1}$ : is the probability that behavioral element $\mathrm{n}$ affects the residents based on their nationality;

$\beta \mathrm{X}_{\mathrm{n} 1}$ : is the utility function that behavioral element $\mathrm{n}$ affects Qataris:

$\beta \mathrm{X}_{\mathrm{n} 2}$ : is the utility function that behavioral element $\mathrm{n}$ affects non-Qataris;

$\Delta U=\beta X_{2 n}-\beta X_{1 n}=\sum\left(a_{i}-b_{i}\right) Z_{i}$, where $Z_{\mathrm{i}}$ is the ith variable; $\mathrm{a}_{\mathrm{i}}$ is the coefficient of the ith variable in $\beta X_{n 1}$; and bi is the coefficient of the ith variable in $\beta X_{n 2}$.

The results of the model are shown in Table 2. The model was able to predict $84.9 \%$ of the entries to fall in their respective groups. Furthermore, the model goodness of fit is $\mathrm{R}^{2}=0.630$ value, which indicates that the model has good explanatory power. The entries of the table show that all the explanatory variables, except for indoor temperature, climate attitude, and rare appliance use, make a significant and substantial contribution to explaining the difference in the behavioral elements between Qataris and non-Qataris in their electricity consumption. The model results show that preference for indoor lighting has a significant influence $(P<0.05)$ on electricity consumption between the two groups. This behavioral element has a positive sign for both dark and moderate indoor lighting, with an odds ratio of 5.495 and 4.800 . This implies that Qataris are more willing to use dark or moderate lighting more than light indoor lighting compared to non-Qataris. The same applies to the extent that residents use electrical appliances. This variable is significant in determining electricity consumption, and the coefficient of this variable is positive for moderate use compared to very frequent use, with an odds ratio of 1.964. This implies that Qataris use electrical appliances in a more moderate way compared to nonQataris. 

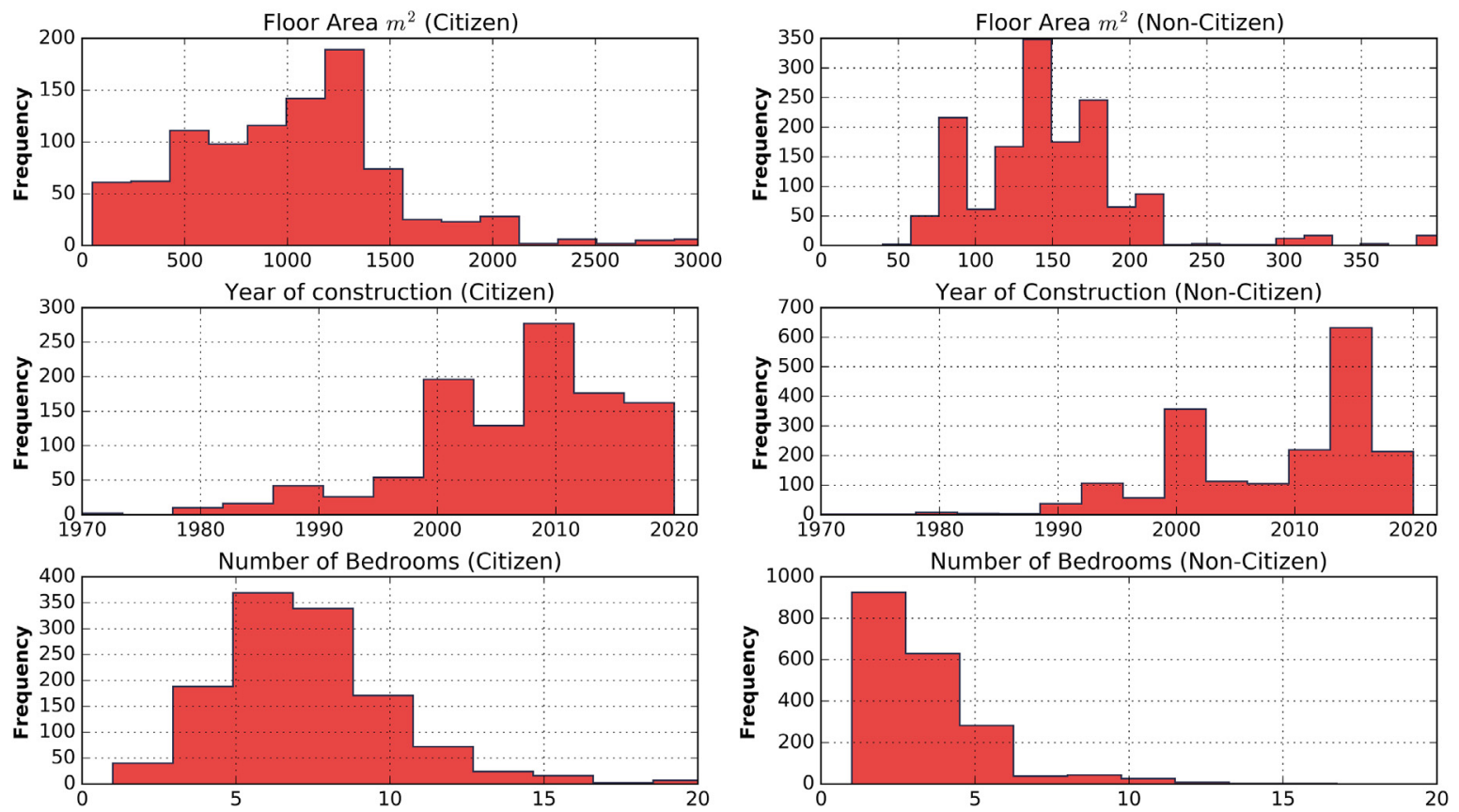

Fig. 10. Distribution of building characteristics based on the survey results.

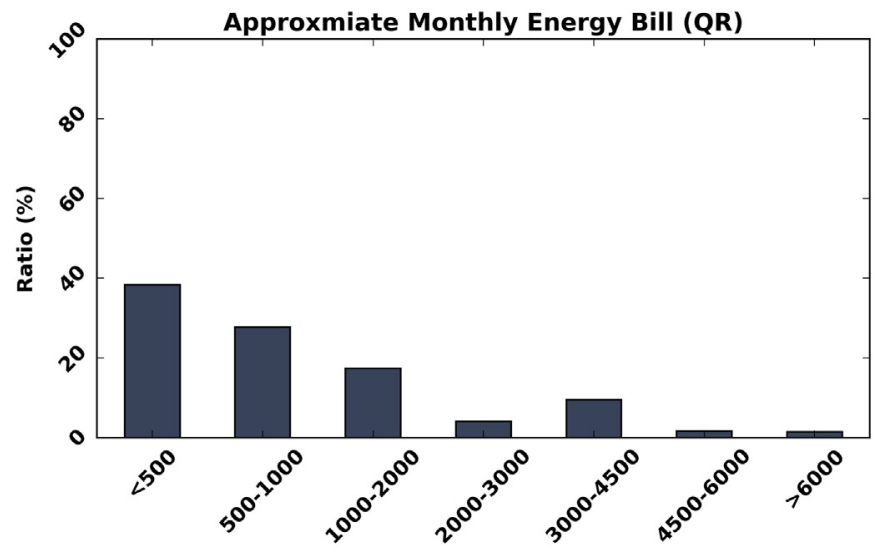

Fig. 11. Distribution of approximate monthly electricity bills reported by the subjects [in Qatari Rials (QR)].

On the other hand, the entries in the table show no significant differences between Qataris and Non-Qataris in using electrical appliances rarely, though non-Qataris use these appliances more often. The residents' willingness to upgrade to use more electrical efficient equipment and to retrofit buildings in respect of energy use shows some discrepancies between Qataris and non-Qataris. This element is significant $(\mathrm{P}<0.05)$ and has a negative sign for "not interested in upgrades," with an odds ratio of 0.642 , and a positive sign of "highly interested," with an odds ratio of 2.047, compared to the "not sure if renovation works" option. This implies that Qataris are willing to pay for renovations/upgrades at home to reduce their energy consumption, and they are more confident about doing so than are non-Qataris. This can be explained by the fact that most of non-Qatari do not own their houses. In addition, Non-Qatari are more financially concerned than Qatari citizens. Furthermore, the entries in the table show that willingness to use smart energy solutions is a significant factor in explaining the consumption behavior among residents. The motivations to use smart energy solutions were based on economic, environmental, and social factors. In terms of personal gains, Qataris and nonQataris show no significant differences $(P=0.117)$. This implies that both Qataris and non-Qataris are willing to use smart energy solutions if it is economically beneficial for them. On the other hand, Qataris are more willing than are non-Qataris to use smart energy solutions if this benefits the environment and society. Finally, monthly household expenses is another significant indicator of household electricity consumption behavior. This coefficient has a negative sign. This implies that as the monthly household expenses increase, the lower the willingness to conserve energy. In addition, compared to non-Qataris, Qataris are less likely to conserve energy if their average monthly expenses increase.

A multinomial Logit (MNL) model has been utilized for assessing the impact of the behavioral factors on electricity consumption. In this model, the electricity bill is considered the independent variable. Respondents were asked to report their average monthly electricity bill. The electricity bill was classified into three categories: 1) less than QR 1000 (\$275), 2) between QR 1000 (\$275) AND QR 2999 (\$824), and 3) more than QR 3000 (\$825). The MNL can be expressed as:

$P(i)=\frac{e^{U_{i}}}{\sum_{j \varepsilon J} e^{U_{i}}}$

where:

$\mathrm{P}(\mathrm{i})$ is the probability of a decision maker choosing alternative $\mathrm{i}$. $\mathrm{U}_{\mathrm{i}}$ and $\mathrm{U}_{\mathrm{j}}$ are the utilities of alternatives $\mathrm{i}$ and $\mathrm{j}$, and.

$\mathrm{J}$ is the number of alternatives.

The MNL was able to predict $85.6 \%$ of the entries to fall in their respective groups, with $\mathrm{R} 2=0.663$. The model results are shown in Table 3. The model shows that indoor temperature is not a significant behavioral element. However, residents who pay less than QR1,000 for the electricity bill per month tend to reduce their preference and usage to cold air in their houses and prefer a more moderate temperature. In addition, the indoor lighting preference is also not a significant behavioral factor; however, residents who 
Table 2

Model parameter estimates for electricity consumption behavior among end users (reference category: non-Qataris).

\begin{tabular}{|c|c|c|c|c|c|c|c|c|}
\hline \multirow[t]{2}{*}{ Behavioral elements } & \multirow[t]{2}{*}{$\beta$} & \multirow[t]{2}{*}{ S.E. } & \multirow[t]{2}{*}{ Wald } & \multirow[t]{2}{*}{ df } & \multirow[t]{2}{*}{ Sig. } & \multirow[t]{2}{*}{$\operatorname{Exp}(\beta)$} & \multicolumn{2}{|c|}{$95 \% \mathrm{CI}$ for $\operatorname{EXP}(\beta)$} \\
\hline & & & & & & & Lower & Upper \\
\hline Indoor Temperature & & & 6.375 & 2 & .041 & & & \\
\hline Cold (below $21^{\circ} \mathrm{C}$ ) & .128 & .225 & .323 & 1 & .570 & 1.136 & .731 & 1.765 \\
\hline Moderate $\left(21^{\circ} \mathrm{C}-23^{\circ} \mathrm{C}\right)$ & .399 & .209 & 3.641 & 1 & .056 & 1.490 & .989 & 2.245 \\
\hline Lighting & & & 140.407 & 2 & .000 & & & \\
\hline Dark & 1.704 & .200 & 72.356 & 1 & .000 & 5.495 & 3.711 & 8.137 \\
\hline Moderate & 1.569 & .140 & 126.185 & 1 & .000 & 4.800 & 3.651 & 6.311 \\
\hline Appliance use & & & 28.963 & 2 & .000 & & & \\
\hline Rare & .102 & .226 & .205 & 1 & .651 & 1.108 & .711 & 1.726 \\
\hline Moderate & .675 & .130 & 27.122 & 1 & .000 & 1.964 & 1.524 & 2.532 \\
\hline Upgrade Willingness & & & 61.692 & 2 & .000 & & & \\
\hline Not interested in upgrades & -.443 & .173 & 6.556 & 1 & .010 & .642 & .457 & .901 \\
\hline Highly interested & .717 & .136 & 27.776 & 1 & .000 & 2.047 & 1.568 & 2.672 \\
\hline Smart Attitude & & & 164.719 & 3 & .000 & & & \\
\hline Agree, if it is economically beneficial for me & -.396 & .253 & 2.452 & 1 & .117 & .673 & .410 & 1.105 \\
\hline Agree, if it helps the environment & 1.239 & .276 & 20.127 & 1 & .000 & 3.451 & 2.009 & 5.930 \\
\hline Agree, if it benefits the society & 1.047 & .267 & 15.415 & 1 & .000 & 2.848 & 1.689 & 4.803 \\
\hline Climate Attitude & & & 1.620 & 2 & .445 & & & \\
\hline Yes & -.173 & .152 & 1.296 & 1 & .255 & .841 & .624 & 1.133 \\
\hline No & -.240 & .241 & .997 & 1 & .318 & .786 & .491 & 1.260 \\
\hline Monthly expenses & & & 427.355 & 3 & .000 & & & \\
\hline Less than $5000 \mathrm{QR}^{*}$ & -3.432 & .171 & 404.439 & 1 & .000 & .032 & .023 & .045 \\
\hline Between 5000 and 9999 QR & -2.236 & .161 & 191.835 & 1 & .000 & .107 & .078 & .147 \\
\hline Between 10,000 and $14,999 \mathrm{QR}$ & -1.485 & .174 & 72.722 & 1 & .000 & .227 & .161 & .319 \\
\hline Constant & -.421 & .328 & 1.647 & & .199 & .656 & & \\
\hline
\end{tabular}

*\$1 USA $=3.64 \mathrm{QR}$.

pay less than QR 1000 per month prefer to use dark to moderate indoor lighting than to use light indoor lighting when compared to those who pay more than QR 3000 per month. The moderate use of appliances is a significant behavioral factor $(P<0.05)$. The coefficient of this factor is positive, with an odds ratio of 4.476 for category 1 (pay less than QR 1000 per month) and 2.234 for category 2 (pay between QR 1000 and QR 2999). The trend shows that as the amount of the bill increases the frequency of use of the appliances increases considerably. The table entries show that residents are not sure whether renovations/upgrades at home work to lower their energy consumption; this is particularly the case for those in the first two categories, as the coefficient of this variable is negative when compared to the third category. The subjects are willing to use smart energy solutions such as central automation and smart thermostats if these elements benefit them economically and also benefit both the environment and their society. The coefficient is significant in the first two categories and has a positive sign. Furthermore, the concern about emission and climate change is a significant factor that encourages subjects to conserve their electricity usage. The coefficient in the first two categories is positive, which indicates that subjects in these two categories are more concerned about the climate than are those who pay more than $\mathrm{QR}$ 3000 per month for electricity.

\subsection{Random forest analysis for feature importance}

In this section, we aim at training a machine learning model to predict the household energy consumption using the following attributes:

- The preferred indoor temperature at home

- The preferred lighting at home

- The extent of electrical appliances' use

- The extent of the willing to pay for renovation at upgrade at home to lower energy consumption

- The stand on smart energy solutions

- The concern about emissions and climate change.
The trained model enables conducting a feature importance analysis to determine the critical behavioral factors. Random Forest is a robust ML algorithm that outperform multiple other algorithms thanks to its design. $\mathrm{RF}$ is an ensemble learning approach that relies on the "wisdom of the crowd". Specifically, multiple decision trees are trained at the same time and the final decision is aggregated (e.g. majority vote) to output the final classification/prediction. Decision trees have the capability of fitting intricate patterns both for classification and regression tasks. There are several decision tree learning algorithms that, in general, have the objective of recursively splitting samples into homogenous subsets (nodes) based on an attribute. The measure of the quality of split is based on metrics such as Gini impurity, defined as:

$G_{i}=1-\sum_{k=1}^{n} p_{i, k}^{2}$

where $G_{i}$ is the Gini impurity of node I, and $p_{i, k}$ is the ratio of class $\mathrm{k}$ among all instances in node $i$. The cost function to train a decision tree based on Gini impurity, CART algorithm to find the optimum split is defined as follows [44]:

$J\left(k, t_{k}\right)=\frac{m_{\text {left }}}{m} G_{\text {left }}+\frac{m_{\text {right }}}{m} G_{\text {right }}$

where $J\left(k, t_{k}\right)$ is the cost function based on feature $\mathrm{k}$, threshold $t_{k}$, $G_{\text {left } / r i g h t}$ is the impurity of the left or right subset, and $m_{\text {left } / \text { right }}$ is the number of instances on the left or right. In a random forest classifier, random sampling is applied to both the training dataset and the feature set. An inherent feature of random forest classifiers is their capability to measure the relative importance of features. The feature importance is determined based on the extent to which a feature, on average, reduces the impurity measure based on Equations (5) and (6).

$N I_{i}=w_{i} G_{i}-w_{\text {right }, i} G_{\text {right }, i}-w_{\text {left }, i} G_{\text {left }, i}$ 
Table 3

The behavioral elements that contribute to explaining the electricity consumption. The reference category is: Monthly Electricity Bill more than 3000 QR.

\begin{tabular}{|c|c|c|c|c|c|c|c|c|c|}
\hline \multirow[t]{2}{*}{ Behavioral Elements } & & \multirow[t]{2}{*}{$\beta$} & \multirow[t]{2}{*}{ S.E. } & \multirow[t]{2}{*}{ Wald } & \multirow[t]{2}{*}{ df } & \multirow[t]{2}{*}{ Sig. } & \multirow[t]{2}{*}{$\operatorname{Exp}(\beta)$} & \multicolumn{2}{|c|}{$95 \% \mathrm{CI}$ for $\operatorname{EXP}(\beta)$} \\
\hline & & & & & & & & Lower & Upper \\
\hline \multicolumn{10}{|c|}{ Category 1: Monthly Electricity Bill - less than $1000 \mathrm{QR}$} \\
\hline \multicolumn{2}{|c|}{ Intercept } & -2.347 & 1.217 & 3.719 & 1 & .054 & & & \\
\hline \multirow[t]{3}{*}{ Indoor Temperature } & Cold (below $21^{\circ} \mathrm{C}$ ) & -1.581 & 1.002 & 2.491 & 1 & .115 & .206 & .029 & 1.466 \\
\hline & Moderate $\left(21^{\circ} \mathrm{C}-23^{\circ} \mathrm{C}\right)$ & .797 & .968 & .677 & 1 & .411 & 2.218 & .333 & 14.798 \\
\hline & Hot (Above $23^{\circ} \mathrm{C}$ ) & $0^{\mathrm{b}}$ & & & 0 & & & & \\
\hline \multirow[t]{3}{*}{ Lighting } & Dark & -1.302 & .747 & 3.032 & 1 & .082 & .272 & .063 & 1.178 \\
\hline & Moderate & -.429 & .415 & 1.066 & 1 & .302 & .651 & .288 & 1.470 \\
\hline & Light & $0^{\mathrm{b}}$ & & & 0 & & & & \\
\hline \multirow[t]{3}{*}{ Appliance use } & Rarely & .366 & .789 & .215 & 1 & .643 & 1.441 & .307 & 6.762 \\
\hline & Moderate & 1.499 & .426 & 12.374 & 1 & .000 & 4.476 & 1.942 & 10.315 \\
\hline & Very Often & $0^{\mathrm{b}}$ & & & 0 & & & & \\
\hline \multirow[t]{3}{*}{ Upgrade Willingness } & Not interested in upgrades & -1.206 & .567 & 4.524 & 1 & .033 & .299 & .099 & .910 \\
\hline & Highly interested & -2.994 & .406 & 54.345 & 1 & .000 & .050 & .023 & .111 \\
\hline & Not sure if renovation works & $0^{\mathrm{b}}$ & & & 0 & & & & \\
\hline \multirow[t]{4}{*}{ Smart Attitude } & Agree, if it is economically beneficial for me & 2.095 & .810 & 6.689 & 1 & .010 & 8.128 & 1.661 & 39.772 \\
\hline & Agree, if it helps the environment & 3.652 & .931 & 15.374 & 1 & .000 & 38.557 & 6.212 & 239.306 \\
\hline & Agree, if it benefits the society & 2.503 & .915 & 7.487 & 1 & .006 & 12.221 & 2.034 & 73.412 \\
\hline & I disagree & $0^{\mathrm{b}}$ & & & 0 & & & & \\
\hline \multirow[t]{3}{*}{ Climate Attitude } & Yes & 1.501 & .519 & 8.364 & 1 & .004 & 4.488 & 1.622 & 12.414 \\
\hline & No & 1.124 & .940 & 1.430 & 1 & .232 & 3.076 & .488 & 19.398 \\
\hline & Not sure & $0^{\mathrm{b}}$ & & & 0 & & & & \\
\hline \multirow[t]{4}{*}{ Monthly expenses } & Less than $5000 \mathrm{QR}^{*}$ & 7.382 & .845 & 76.243 & 1 & .000 & 1607.243 & 306.499 & 8428.186 \\
\hline & Between 5000 and 9999 QR & .968 & .480 & 4.058 & 1 & .044 & 2.632 & 1.027 & 6.747 \\
\hline & Between 10,000 and $14,999 \mathrm{QR}$ & 4.273 & .583 & 53.795 & 1 & .000 & 71.739 & 22.901 & 224.729 \\
\hline & $15,000 \mathrm{QR}$ or more & $0^{\mathrm{b}}$ & & & 0 & & & & \\
\hline \multicolumn{10}{|c|}{ Category 2: Monthly Electricity Bill - Between 1000 and 3000 QR } \\
\hline Intercept & & .080 & 1.108 & .005 & 1 & .942 & & & \\
\hline Indoor Temperature & Cold (below $21^{\circ} \mathrm{C}$ ) & -1.153 & .931 & 1.532 & 1 & .216 & .316 & .051 & 1.959 \\
\hline & Moderate $\left(21^{\circ} \mathrm{C}-23^{\circ} \mathrm{C}\right)$ & .426 & .911 & .219 & 1 & .640 & 1.531 & .257 & 9.123 \\
\hline & Hot (Above $\left.23^{\circ} \mathrm{C}\right)$ & $0^{\mathrm{b}}$ & & & 0 & & & & \\
\hline Lighting & Dark & .817 & .672 & 1.480 & 1 & .224 & 2.265 & .607 & 8.451 \\
\hline & Moderate & .320 & .391 & .667 & 1 & .414 & 1.377 & .639 & 2.964 \\
\hline & Light & $0^{\mathrm{b}}$ & & & 0 & & & & \\
\hline Appliance use & Rare & .015 & .722 & .000 & 1 & .984 & 1.015 & .246 & 4.182 \\
\hline & Moderate & .804 & .402 & 3.991 & 1 & .046 & 2.234 & 1.015 & 4.914 \\
\hline & Very Often & $0^{\mathrm{b}}$ & & & 0 & & & & \\
\hline Upgrade Willingness & Not interested in upgrades & -2.450 & .569 & 18.550 & 1 & .000 & .086 & .028 & .263 \\
\hline & Highly interested & -2.628 & .383 & 47.131 & 1 & .000 & .072 & .034 & .153 \\
\hline & Not sure if renovation works & $0^{\mathrm{b}}$ & & & 0 & & & & \\
\hline Smart Attitude & Agree, if it is economically beneficial for me & 1.574 & .730 & 4.646 & 1 & .031 & 4.828 & 1.153 & 20.209 \\
\hline & Agree, if it helps the environment & 2.168 & .863 & 6.309 & 1 & .012 & 8.741 & 1.610 & 47.453 \\
\hline & Agree, if it benefits the society & 1.271 & .830 & 2.343 & 1 & .126 & 3.563 & .700 & 18.132 \\
\hline & I disagree & $0^{\mathrm{b}}$ & & & 0 & & & & \\
\hline Climate Attitude & Yes & 1.208 & .474 & 6.494 & 1 & .011 & 3.347 & 1.322 & 8.474 \\
\hline & No & .537 & .895 & .360 & 1 & .548 & 1.711 & .296 & 9.879 \\
\hline & Not sure & $0^{\mathrm{b}}$ & & & 0 & & & & \\
\hline Monthly expenses & Less than $5000 \mathrm{QR}^{*}$ & 2.854 & .809 & 12.448 & 1 & .000 & 17.354 & 3.555 & 84.701 \\
\hline & Between 5000 and 9999 QR & -.217 & .385 & .318 & 1 & .573 & .805 & .378 & 1.712 \\
\hline & Between 10,000 and $14,999 \mathrm{QR}$ & 2.006 & .505 & 15.808 & 1 & .000 & 7.436 & 2.766 & 19.993 \\
\hline & $15,000 \mathrm{QR}$ or more & $0^{\mathrm{b}}$ & & & 0 & & & & \\
\hline
\end{tabular}

$F I_{i}=\frac{\sum_{j: \text { node } j \text { splits on feature } i} N I_{j}}{\sum_{j \in \text { all nodes }} N I_{j}}$

where $N I_{i}$ is the importance of node $\mathrm{i}, \mathrm{w}$ is the weighted number of instances, and $F I_{i}$ is the importance of feature i. $F I_{i}$ is a ratio, in which the values closer to 1 contain more variance and information to determine the class of a target variable based on the feature's splitting frequency during CART algorithm.

Multiple random forest classifiers were constructed with the objective of measuring the relative importance of each behavioral factor with respect to the main target variables. The random forest models were based on an ensemble of 500 decision tree classifiers trained via the bootstrap algorithm, random patches method, and Gini impurity. Based on a cross-validation analysis with 10 folds, the random forest estimators are capable of classifying the target variables based on the each set of exogenous variables according to Table 4. Although the model accuracy is not as high as possible due to the human driven factors and the reliability of self-perceived inputs, the classifiers still possess a significant amount of information to differentiate the consumption patterns within the sample along with local/expatriate communities. Fig. 12 shows the patterns of the feature importance analysis for the aforementioned classifiers and averaged based on 1000 runs. As seen in Fig. 12, indoor thermal comfort preference, respondent's willingness toward home upgrades, and self-perceived appliance use are among the important features containing information to classify monthly electricity bills. Building construction year and floor area demonstrate the highest feature importance values associated with the building features, and among demographic/socioeconomic factors 
income and education show significant feature importance values to classify monthly electricity bills. Besides, within local and expatriate communities, willingness towards home upgrades, home energy efficiency motivations and indoor lighting preference possesses a significant amount of information to differentiate the two communities. The similar analysis in any population can provide insight what human driven factors must be prioritized in energy policy.

\subsection{Clustering of socioeconomic and behavioral factors}

A k-means clustering model [47] was used to identify how socioeconomic and behavioral factors can form various segments in the target population with similar energy-oriented traits. This segmentation can simplify human-energy strategic planning so that a set of traits, as a whole, can be attributed to a community in order to target multiple relevant concerns simultaneously. Among several permutations of human drivers, two sets of traits are selected as (1) energy use behavior and HBI factors (Table 5), and (2) a combination of socioeconomic factors, education and income, and attitudes towards home energy efficiency motivations, climate change, and home retrofit (Table 6). The Elbow-method [48] was used to find the optimal number of clusters factors as being 4 for both models.

As shown in tbl5Tables 5 and 6'tbl6, different groups with different attitudes can be identified. According to Table 5, those in cluster 4 show high consumption of air conditioning, lighting, and appliances are the only cluster with high energy use category, which can be intuitively validated. Besides, Table 4 demonstrates a cluster of respondents (cluster 4), in which the subjects show adverse attitudes towards energy topics and they fall into a lowincome category and with a bachelor's degree. To this end, based on the decision-maker's strategy, using unsupervised learning approaches, such as k-means clustering, can potentially help to create main targeted segments with similar traits.

\section{Simulations}

\subsection{Building simulation}

As demonstrated previously, air conditioning constitutes the largest proportion of energy consumption of residential buildings in Qatar. Therefore, human indoor temperature preference (as the main factor in air conditioning demand) can become a major target in shaping new behaviors associated with residential energy consumption. Temperature preference as a behavioral factor was introduced previously as cold (less than $22{ }^{\circ} \mathrm{C}$ ), moderate $\left(22{ }^{\circ} \mathrm{C}-24{ }^{\circ} \mathrm{C}\right.$ ), and hot (greater than $24{ }^{\circ} \mathrm{C}$ ) indoor temperature categories. To estimate the impact of establishing habitual new preferences in indoor temperature for different residential buildings on energy consumption at an aggregate level, electricity consumption must be estimated as a function of indoor temperature setpoint, floor area, and building type. We categorize the buildings in Doha, Qatar, into two major types: Palaces/Villas and Apartments. Approximately 180 EnergyPlus building simulations were conducted to find the annual building electricity consumption for fixed indoor temperature setpoints that range from $20{ }^{\circ} \mathrm{C}$ to $26{ }^{\circ} \mathrm{C}$ (within ASHRAE 55 thermal comfort zone [49]), floor areas from 50 $\mathrm{m} 2$ to $1600 \mathrm{~m} 2$, and two different building types. We note that we have opted for a wide range of floor areas in order to accommodate the discrepancy between citizens and non-citizens in terms of the house type and area as Qatari live in more spacious households, villas and palaces while most of expatriates opt for apartments. The simulations were all deterministic with no stochasticity in terms of occupancy, weather conditions, lighting use, and appliance use. Therefore, the sensitivity analysis was only conducted on various cooling loads and floor areas with other input variables as being fixed. The simulation results are shown in Fig. 13. All the simulations are based on simplified assumptions similar to the model presented in section 2 (ASHRAE 189.1 and 90.1 standards, climate zone $1 \mathrm{~B}$ assumptions, ducted packaged air conditioner, and TMY2 weather condition). Although the sample does not represent the exact building stock in Doha, but they provide an estimation about the role of cooling load in electricity consumption at an aggregate level. The outcome was implemented in different what-if scenarios to assess energy savings as a result of establishing habitual new indoor temperature preferences.

To avoid running building simulations for all input ranges, a multi-linear regression was constructed to estimate the annual electricity consumption based on Equation (7).

$\widehat{y}=\theta_{0}+\theta_{1} x_{1}+\theta_{2} x_{2}$

where $\hat{y}$ is the estimated annual electricity consumption, $x_{i}$ variables are indoor temperature and floor area as inputs, and $\theta_{i}$ is a model parameter. Equation (6) was trained based on 180 data points for two different building types and based on a mean squared error cost function to find the optimal model parameters, as below:

$J(\theta)=\frac{1}{m} \sum_{i=1}^{m}\left(y-\left(\theta_{0}+\theta_{1} x_{1}+\theta_{2} x_{2}\right)\right)^{2}+\alpha \frac{1}{2} \sum_{i=1}^{2} \theta_{i}^{2}$

where $J(\theta)$ is the model cost function, $\mathrm{y}$ is the actual annual electricity consumption, $\mathrm{m}$ is the total number of the instances, and $\alpha$ is a regularization term to avoid overfitting. The cost function combines two terms: the first one models the mean square error between the model prediction and the actual values. The second term is added for regularization purpose to avoid overfitting. The model parameters are demonstrated in Table 7.

Having an estimation of annual electricity consumption for different indoor temperature ranges and floor areas, we were able to estimate the household electricity consumption for the sample based on the acquired information. The analysis was categorized into 4 case scenarios:

- Scenario 1: or the reference scenario, where all consumption estimates are based on the reported indoor temperature preferences in the sample (Fig. 10).

- Scenario 2: all the end-users with a cold indoor temperature preference switch to a moderate indoor temperature, and the

Table 4

The model accuracy of the random forest classifiers with respect to the target variables and exogenous set of variables.

\begin{tabular}{lll}
\hline Target Variables & Set of Exogenous Variables & Average Model Accuracy \\
\hline Monthly Bill & Behavioral Factors & $81.2 \%$ \\
Monthly Bill & Building Features & $76.6 \%$ \\
Monthly Bill & Demographic/Socioeconomic Factors & $84.6 \%$ \\
Citizenship Category & Behavioral Factors & $84.3 \%$ \\
\hline
\end{tabular}



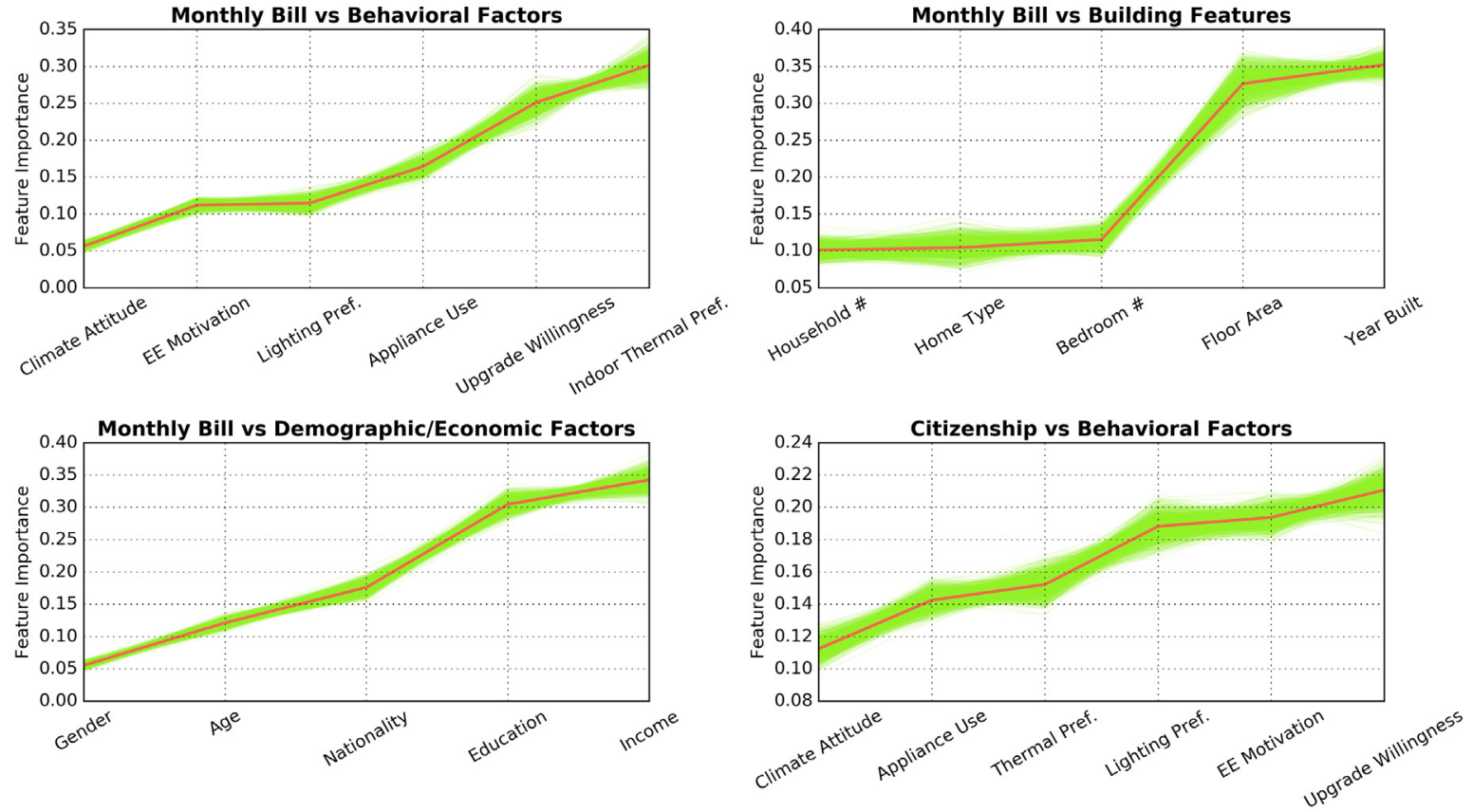

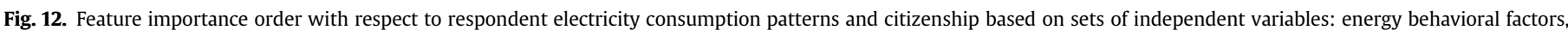

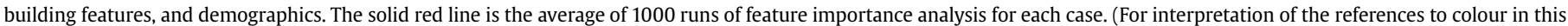
figure legend, the reader is referred to the Web version of this article.)

Table 5

Forming various groups based on HBI factors and consumption patterns via k-means clustering.

\begin{tabular}{|c|c|c|c|c|}
\hline Attribute & Indoor Temperature preference & Lighting Preference & Appliance Use & Energy Use \\
\hline \multicolumn{5}{|c|}{ Cluster Label } \\
\hline 1 & Cold & Dark & Moderate & Low \\
\hline 2 & Moderate & Light & High & Low \\
\hline 3 & Moderate & Moderate & Moderate & Low \\
\hline 4 & Cold & Light & High & High \\
\hline
\end{tabular}

Table 6

Forming various groups based on socioeconomic factors and energy attituded of the respondents via k-means clustering.

\begin{tabular}{|c|c|c|c|c|c|}
\hline Attribute & Education & Income & Home Upgrade Willingness & EE Motivation & Climate Change Awareness \\
\hline \multicolumn{6}{|c|}{ Cluster Label } \\
\hline 1 & Master & $30 \mathrm{k} \mathrm{QR}-40 \mathrm{k}$ QR & Agree & Economic & Concerned \\
\hline 2 & High School & $<10 \mathrm{k} \mathrm{QR}$ & Disagree & Economic & Concerned \\
\hline 3 & Master & $20 \mathrm{k} \mathrm{QR}-30 \mathrm{k} \mathrm{QR}$ & Agree & Economic & Concerned \\
\hline 4 & Bachelor & $<10 \mathrm{k} \mathrm{QR}$ & Disagree & No Motivations & Indifferent \\
\hline
\end{tabular}

remaining temperature preferences are assumed to be unchanged.

- Scenario 3: all the end-users with a cold indoor temperature preference switch to a moderate indoor temperature, and the end-users with a moderate indoor temperature switch to a hot indoor temperature.

- Scenario 4: all the end-users switch to a hot indoor temperature preference.

To construct the aforementioned scenarios for the individual users in the sample, the user's home floor area and indoor temperature value were required to estimate the annual electricity consumption of the user based on Equation (5). In the sample data, the floor area of the residential buildings were acquired (Fig. 10). However, due to the fact that self-perceived indoor temperature preference was based on qualitative temperature range categories and the actual values were unknown, indoor temperature setpoint values were estimated based on a Gaussian distribution with a standard deviation of $1{ }^{\circ} \mathrm{C}$ and mean values of $21^{\circ} \mathrm{C}, 23^{\circ} \mathrm{C}$, and $25{ }^{\circ} \mathrm{C}$ for cold, moderate, and hot indoor temperature preferences, respectively as below (Fig. 14).

$\left\{\begin{array}{l}T_{\text {random, cold } \sim N\left(21{ }^{\circ} \mathrm{C}, 1^{\circ} \mathrm{C}\right)} \\ T_{\text {random, moderate } \sim N\left(23^{\circ} \mathrm{C}, 1^{\circ} \mathrm{C}\right)} \\ T_{\text {random, hot } \sim N\left(225^{\circ} \mathrm{C}, 1^{\circ} \mathrm{C}\right)}\end{array}\right.$

Equation (7) was used to estimate the annual electricity consumption based on the random indoor temperature distributions in Fig. 14 and the reported building types and floor areas in the survey according to Fig. 10. It should be noted that the four house types used in the survey were simplified to villas/palaces and apartments 

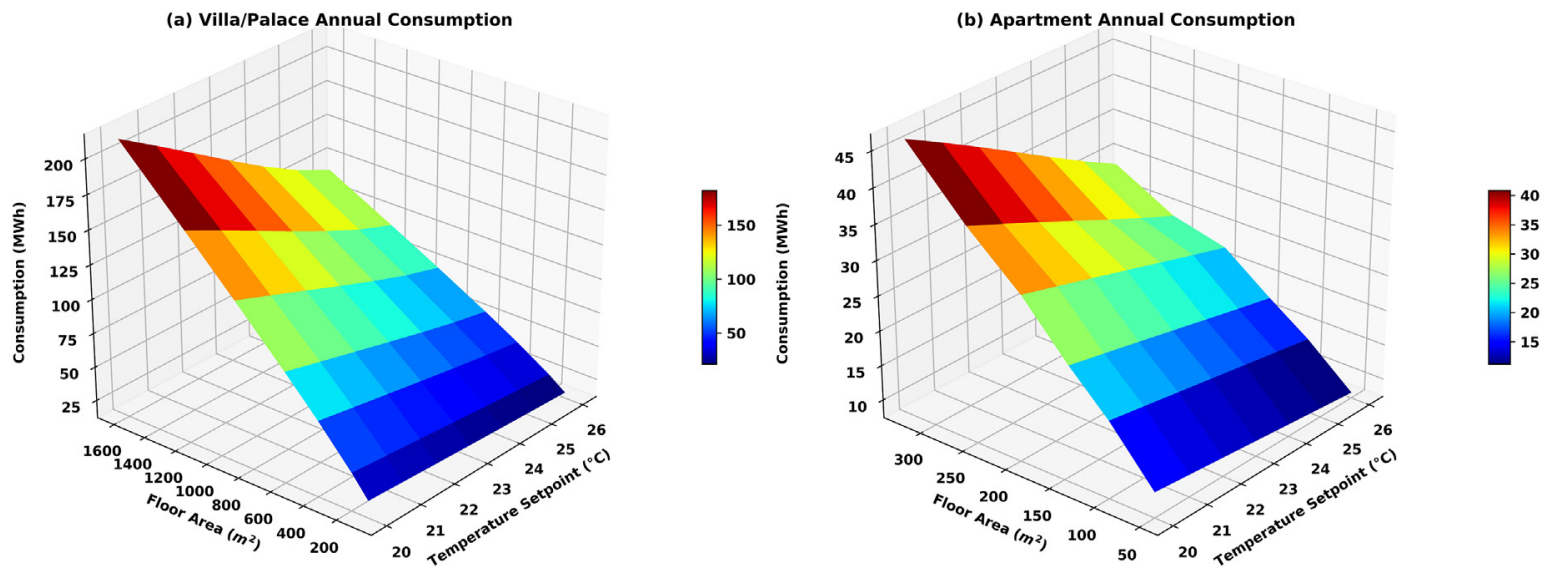

Fig. 13. Annual energy consumption as a function of building floor area and indoor temperature setpoint for single-family and apartment building types.

Table 7

Annual consumption estimator model parameters for two building types.

\begin{tabular}{lllll}
\hline & $\boldsymbol{R}^{2}$ & $\boldsymbol{\theta}_{0}$ & $\boldsymbol{\theta}_{1}$ & $\boldsymbol{\theta}_{2}$ \\
\hline Villa/Palace & 0.961 & $188.17(\mathrm{t}=10.8)$ & $0.09(\mathrm{t}=32.2)$ & $-7.58(\mathrm{t}=-10.1)$ \\
Apartment & 0.964 & $484.89(11.4)$ & $1.2(\mathrm{t}=30.7)$ & $-18.1(\mathrm{t}=-9.9)$ \\
\hline
\end{tabular}

in this analysis. Annual energy consumption estimation was calculated for the sample data (3200 annual consumptions) and the impact of indoor temperature variation on energy consumption was modeled for all the case scenarios to find the total estimated energy consumption of the sample under different indoor temperature preferences. The results of four different scenarios for the aggregate annual electricity consumption of the sample are demonstrated in Fig. 15. As seen in this figure, a saving of from 4 to $15 \%$ in total electricity consumption of the residential buildings can be achieved for the sample. This energy consumption reduction is
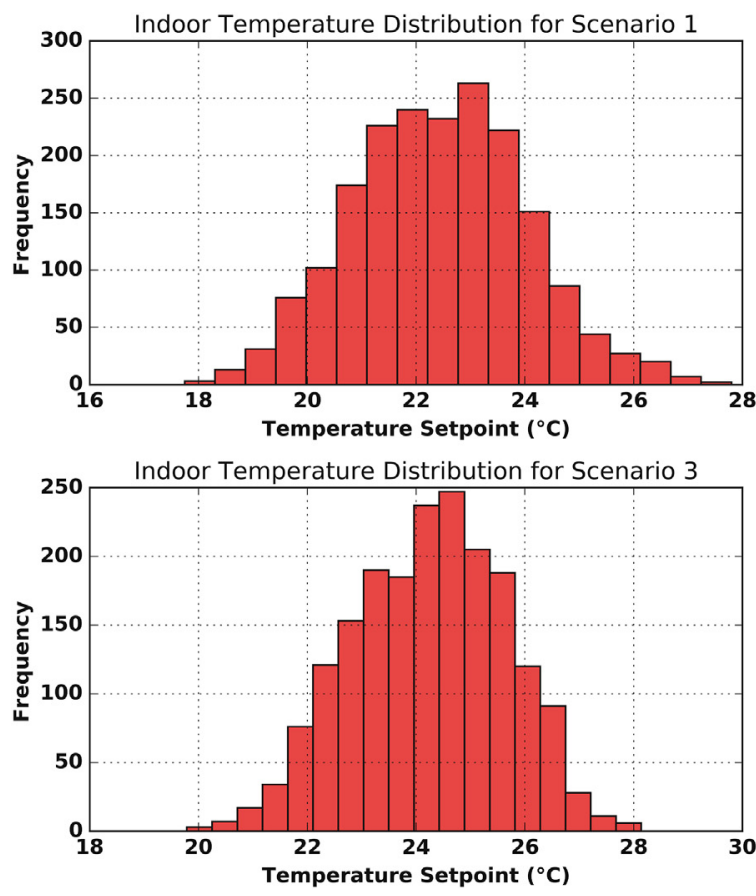

approximately $23 \mathrm{GWh}$ to almost $74 \mathrm{GWh}$ of savings, which is a noticeable change.

\subsection{Random sampling process and aggregate behavior simulation}

To extend the insight from the sample to the Doha municipality and generate data from statistical simulations, it was assumed that the aggregate statistics of the sample represent the population. Two sets of discrete probability distributions were estimated, according to the sample data, for building type and indoor temperature preference. Also, Gaussian Kernel Density [50] functions were estimated, based on the sample distribution, for floor areas, and, for villa/palace and apartment types. Fig. 16 demonstrates density estimations and generated data for two sets of 100,000 instances. Given Qatar's 2015 census data and the estimations for the 2018 households, it was assumed that the Doha municipality consists of 150,000 households. The estimated aggregate annual electricity demand for 150,000 households and under 4 what-if scenarios
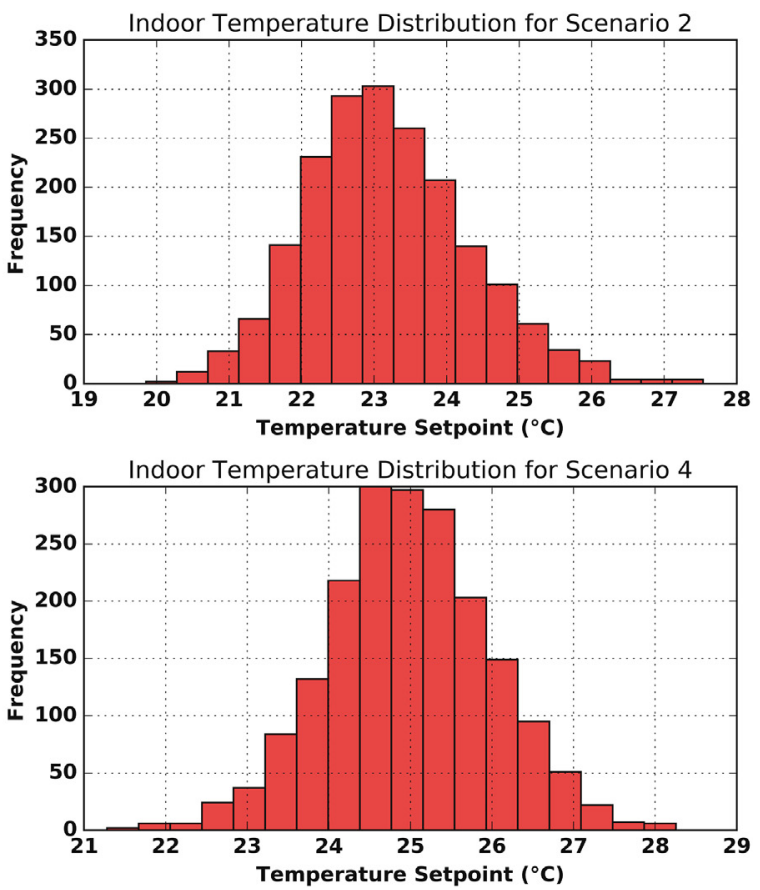

Fig. 14. Generated indoor temperature based on a Gaussian distribution for all 4 case scenarios. 


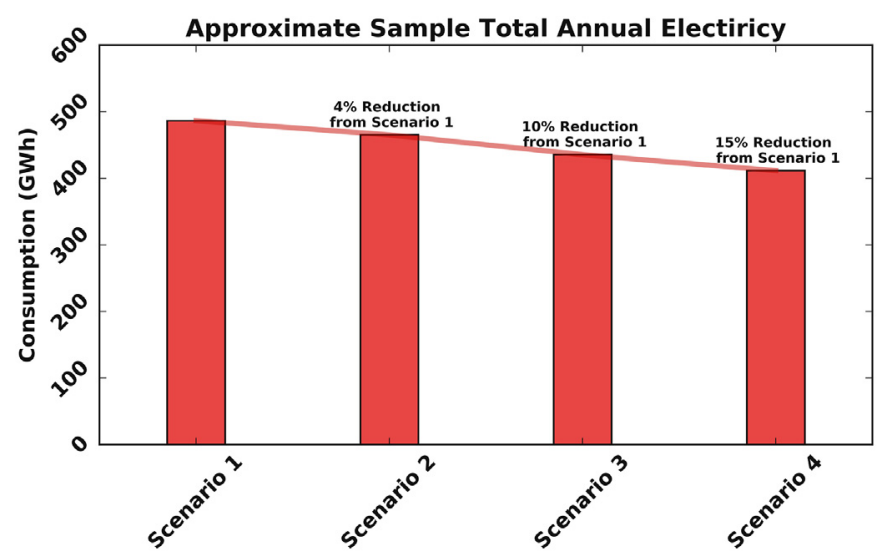

Fig. 15. Energy savings as a result of adopting new temperature setpoints in scenarios 2 to 4 for the sample data.

introduced previously are presented in Fig. 17. Based on the results, the savings can vary from 4 to $16 \%$ under different scenarios associated with human behavior and indoor temperature preference.

The aggregate savings show substantial changes in electricity consumption. Given that the electricity is all supplied by gas-fired power plants, the energy saving and emission reduction [51] with respect to each case scenario will result in Table 8 .

\section{Conclusion and policy recommendations}

The framework presented in this study was designed to find the main socioeconomic and behavioral factors impacting energy consumption in residential buildings. The analysis was based on a survey among a sample size of 3200 subjects in Doha, Qatar, to understand the pre-decisional phase distribution of energy consumption and human preference (indoor temperature, lighting, and appliance use) and targets for a transition to an actional phase and policy planning in the energy sector. The study tried to compare the attributes of two different communities of Qatari citizens (with benefits and energy subsidies) and non-citizens to investigate the impact of energy subsidies on energy conservation attitude and consumption behavior. The results demonstrate that a community that benefits from energy subsidy does not necessarily show weak signs of perceived responsibility and normative goals. The results indicate that citizens, in general, are more concerned about climate change and social outcomes of energy conservation compared to non-citizens, whose concerns are more economical in respect of energy conservation. This seems to be a result of income level and socioeconomic factors. Consequently, energy policy planning can be formed to incentivize other nationalities toward assuming responsibility and normative goals via motivation, opportunity, and ability factors. There is more positive feedback from citizens regarding the inclination toward retrofitting and upgrading than can be justified by the house ownership and income levels. Retrofitting pre-decisional uncertainty can be addressed with tax rebates, incentives, training, education, and advertisement. Both groups show high concern about climate change, though approximately $20 \%$ of the sample remain either uncertain or negative, which finding necessitates creating greater insight about the severity of climate change in society. In addition, the citizens demonstrate low energy-consumption behavior (moderate indoor temperature, indoor lighting, and appliance use) compared to the non-citizens, with high-consumption preferences that cannot be justified by income level. The high consumption patterns can be mitigated by different intervention strategies, such as energy pricing schemes. It also can be addressed by launching awareness campaigns to encourage the different communities about the environment. Indeed, our findings show that a slight change of AC setpoint can contribute in electricity saving while consumer stays in his comfort zone. The feature importance analysis also demonstrates, on the one hand, that monthly expenses, upgrade willingness, and energy conservation attitude are the most critical features that differentiate the two communities.

On the other hand, the feature importance and analytical results demonstrate that indoor temperature preference has a high impact
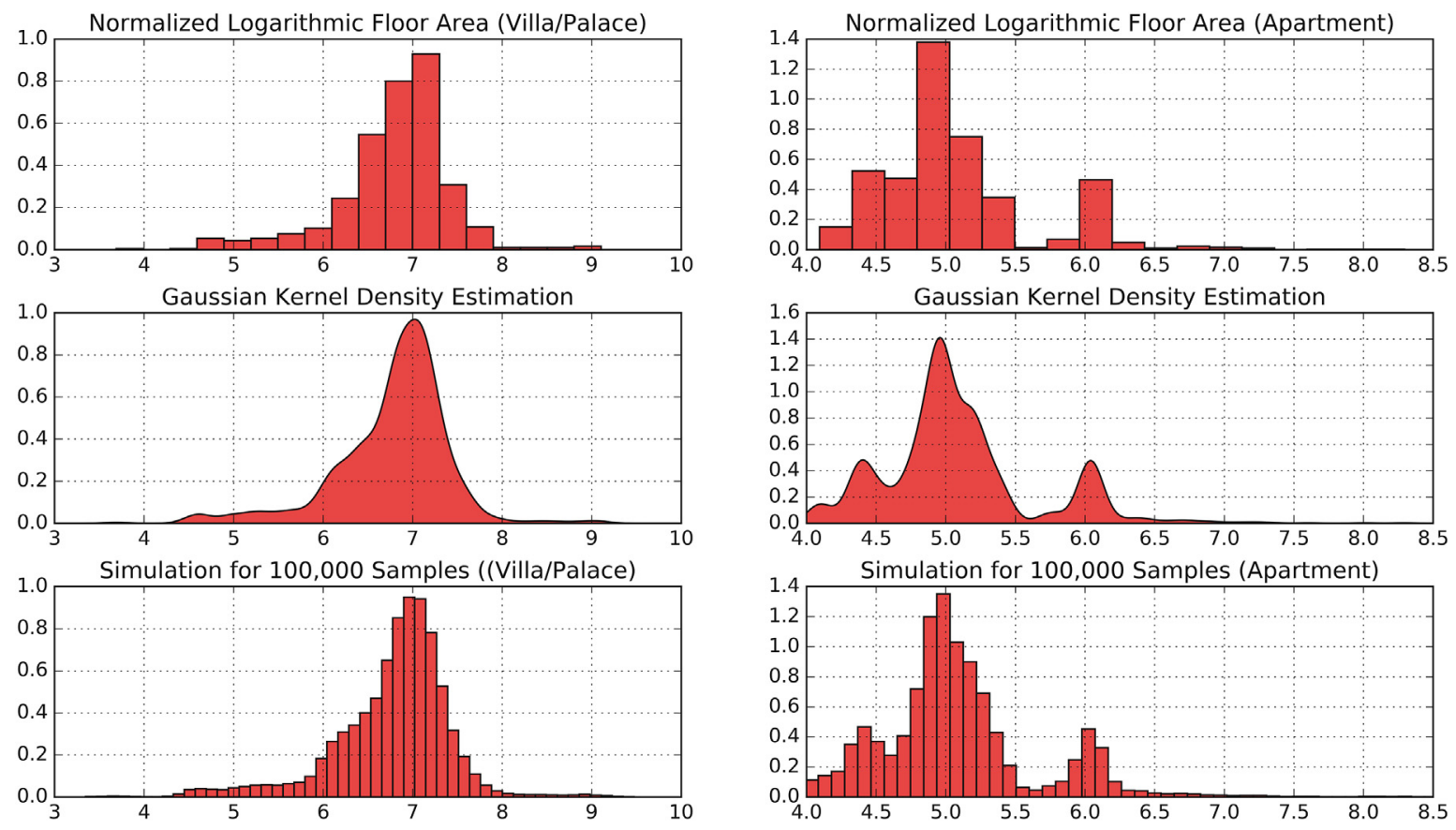

Fig. 16. Kernel density estimation for the distribution of floor area for different building types in the sample. 


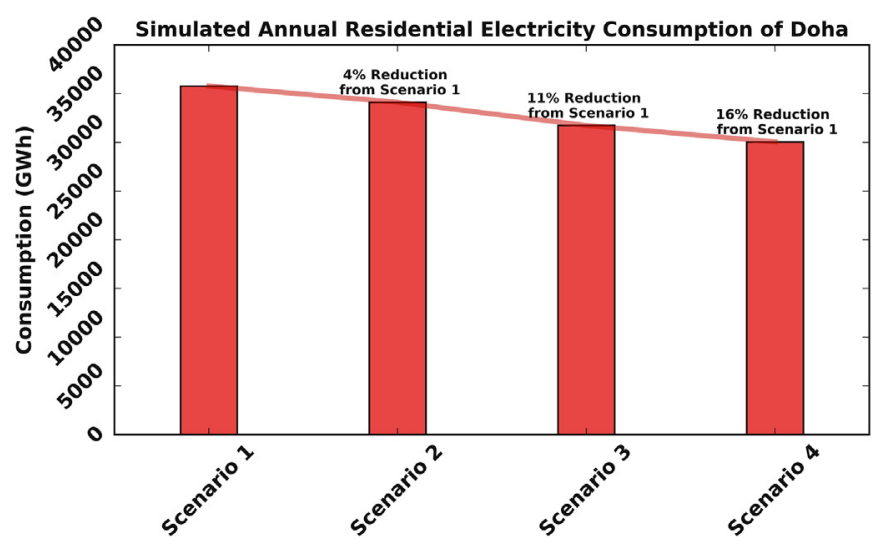

Fig. 17. Savings based on simulation results based on 150,000 households in Doha.

Table 8

Energy savings and emission reduction compared to the reference scenario for aggregate level what-if scenarios.

\begin{tabular}{llll}
\hline & Scenario 2 & Scenario 3 & Scenario 4 \\
\hline Energy Saving $(\mathrm{GWh})$ & 1561.6 & 4056.71 & 5633.97 \\
$\mathrm{CO} 2$ Reduction $\left(10^{6} \mathrm{~kg}\right)$ & 803.95 & 2088.5 & 2900.52 \\
$\mathrm{NO}_{\mathrm{x}}$ Reduction $\left(10^{6} \mathrm{~kg}\right)$ & 1.41666 & 3.68 & 5.11 \\
\hline
\end{tabular}

on the monthly energy bill. Thus, a simulation was designed to evaluate the impact of indoor temperature preference on the sample and population in different what-if scenarios. The simulation results show that if indoor temperature preferences can be reshaped, a noticeable saving amount, of $4 \%-16 \%$, can be achieved in aggregate annual residential consumption in Doha municipality. The reduction in energy consumption can have environmental and economic benefits, such as considerable emission reduction and T\&D (Transmission and Distribution) upgrade deferral. However, this transition in residential indoor temperature cannot necessarily be achieved only by establishing habitual new behaviors but also requires the use of interactive energy efficiency solutions, such as smart control, and intervention practices, such as energy pricing. That is, smart thermostats, central control, and dynamic pricing have the potential to achieve the aforementioned energy savings. Evaluation of the long-term benefits will require a separate economy study. In addition, building energy efficiency must be addressed with great consideration as it is a significant factor affecting energy consumption. For example, in 1995, Hong Kong government issued The Building Energy Efficiency Regulation and applied it for commercial buildings and hotels. Such policies have shown great reduction in energy consumption in China [52] where $65 \%$ adoption of the standard contributed in reducing cooling and heating electricity use while 50\% adoption lead to $38 \%$ reduction. We note also this research study did not take into account the efficiency of AC systems. In future work, we will attempt to collect these information and refine the study findings accordingly.

\section{Credit author statement}

Ali Ghofrani: Data Curation, Conceptualization Methodology, Software, Formal analysis, Writing - Original Draft, Visualization. Esmat Zaidan: Research Conceptualization, Research Design, Methodology, Data Analysis, Writing, Project Administration, Supervision, Resources, Funding Acquisition, Review \& Editing. Ammar Abulibdeh: Investigation, Validation, Writing - Review \& Editing.

\section{Declaration of competing interest}

The authors declare that they have no known competing financial interests or personal relationships that could have appeared to influence the work reported in this paper.

\section{Acknowledgment}

This publication was made possible by an NPRP award [NPRP11S-1228-170142] from the Qatar National Research Fund (a member of Qatar Foundation). The statements made herein are solely the responsibility of the authors. The publication of this article was funded by the Qatar National Library.

\section{References}

[1] Vandenbergh MP, Stern PC, Gardner GT, Dietz T, Gilligan J. Implementing the behavioral wedge: designing and adopting effective carbon emissions reduction programs. Environ Law Rep 2010;40.

[2] Steg L, Perlaviciute G, van der Werff E. Understanding the human dimensions of a sustainable energy transition. Front Psychol Jun. 2015;6:805. https:// doi.org/10.3389/fpsyg.2015.00805.

[3] Thomas S, Rosenow J. Drivers of increasing energy consumption in Europe and policy implications. Energy Pol 2019:111108. https://doi.org/10.1016/ j.enpol.2019.111108.

[4] Uribe-Toril J, Ruiz-Real LJ, Milán-García J, de Pablo Valenciano J. Energy, economy, and environment: a worldwide research update. Energies 2019;12(6). https://doi.org/10.3390/en12061120.

[5] Labanca N, Bertoldi P. Beyond energy efficiency and individual behaviours: policy insights from social practice theories. Energy Pol 2018;115:494-502. https://doi.org/10.1016/j.enpol.2018.01.027.

[6] Sovacool BK. What are we doing here? Analyzing fifteen years of energy scholarship and proposing a social science research agenda. Energy Res. Soc Sci. 2014;1:1-29. https://doi.org/10.1016/j.erss.2014.02.003.

[7] Bamberg S. Applying the stage model of self-regulated behavioral change in a car use reduction intervention. J Environ Psychol 2013;33:68-75. https:// doi.org/10.1016/j.jenvp.2012.10.001.

[8] Stern PC, Sovacool BK, Dietz T. Towards a science of climate and energy choices. Towar. a Sci. Clim. energy choices 2016:547-55.

[9] Stern PC. How can social science research become more influential in energy transitions? Energy Res. Soc. Sci. 2017;26:91-5. https://doi.org/10.1016/ j.erss.2017.01.010

[10] D'Oca S, Hong T, Langevin J. The human dimensions of energy use in buildings: a review. Renew Sustain Energy Rev 2018;81:731-42. https://doi.org/ 10.1016/j.rser.2017.08.019.

[11] A. Heydarian et al., "What drives our behaviors in buildings? A review on occupant interactions with building systems from the lens of behavioral theories," Build Environ, vol. 179, 2020, doi: 10.1016/j.buildenv.2020.106928.

[12] Rinaldi A, Schweiker M, Iannone F. On uses of energy in buildings: extracting influencing factors of occupant behaviour by means of a questionnaire survey. Energy Build 2018;168:298-308. https://doi.org/10.1016/ j.enbuild.2018.03.045.

[13] Bhattacharjee S, Reichard G, McCoy A, Pearce A, Beliveau Y. Identification of elements to control and regulate residential energy consumption. Adv Build Energy Res Jul. 2014;8(2):174-95. https://doi.org/10.1080/ 17512549.2013.865552.

[14] Mills B, Schleich J. Residential energy-efficient technology adoption, energy conservation, knowledge, and attitudes: an analysis of European countries. Energy Pol 2012;49:616-28. https://doi.org/10.1016/j.enpol.2012.07.008.

[15] Guerra-Santin O, Herrera NR, Cuerda E, Keyson D. Mixed methods approach to determine occupants' behaviour - analysis of two case studies. Energy Build 2016;130:546-66. https://doi.org/10.1016/j.enbuild.2016.08.084.

[16] D. M. Koupaei, T. Song, K. S. Cetin, and J. Im, "An assessment of opinions and perceptions of smart thermostats using aspect-based sentiment analysis of online reviews," Build Environ, vol. 170, 2020, doi: 10.1016/ j.buildenv.2019.106603.

[17] Li D, Menassa CC, Karatas A. Energy use behaviors in buildings: towards an integrated conceptual framework. Energy Res. Soc. Sci. 2017;23:97-112. https://doi.org/10.1016/j.erss.2016.11.008.

[18] Adua L. Reviewing the complexity of energy behavior: technologies, analytical traditions, and household energy consumption data in the United States. Energy Res. Soc. Sci. 2020;59:101289. https://doi.org/10.1016/ j.erss.2019.101289.

[19] Moezzi M, Janda KB. From 'if only' to 'social potential' in schemes to reduce building energy use. Energy Res. Soc. Sci. 2014;1:30-40. https://doi.org/ 10.1016/j.erss.2014.03.014.

[20] Gliedt T, Hoicka CE. Energy upgrades as financial or strategic investment? Energy Star property owners and managers improving building energy 
performance. Appl Energy 2015;147:430-43. https://doi.org/10.1016/ j.apenergy.2015.02.028.

[21] Hong T, Yan D, D'Oca S, fei Chen C. Ten questions concerning occupant behavior in buildings: the big picture. Build Environ 2017;114:518-30. https://doi.org/10.1016/j.buildenv.2016.12.006.

[22] Jensen CL, et al. Towards a practice-theoretical classification of sustainable energy consumption initiatives: insights from social scientific energy research in 30 European countries. Energy Res. Soc. Sci. 2018;45:297-306. https:// doi.org/10.1016/j.erss.2018.06.025.

[23] Ohnmacht T, Schaffner D, Weibel C, Schad H. Rethinking social psychology and intervention design: a model of energy savings and human behavior. Energy Res. Soc. Sci. 2017;26:40-53. https://doi.org/10.1016/ j.erss.2017.01.017.

[24] De Young R. Changing behavior and making it stick: the conceptualization and management of conservation behavior. Environ Behav May 1993;25(3): 485-505. https://doi.org/10.1177/0013916593253003.

[25] Wang J, Zhong H, Wu C, Du E, Xia Q, Kang C. Incentivizing distributed energy resource aggregation in energy and capacity markets: an energy sharing scheme and mechanism design. Appl Energy 2019;252:113471. https:// doi.org/10.1016/j.apenergy.2019.113471.

[26] Villca-Pozo M, Gonzales-Bustos JP. Tax incentives to modernize the energy efficiency of the housing in Spain. Energy Pol 2019;128:530-8. https:// doi.org/10.1016/j.enpol.2019.01.031.

[27] Kowalska-Pyzalska A. What makes consumers adopt to innovative energy services in the energy market? A review of incentives and barriers. Renew Sustain Energy Rev 2018;82:3570-81. https://doi.org/10.1016/ j.rser.2017.10.103.

[28] Gerarden T, Newell RG, Stavins RN. Deconstructing the energy-efficiency gap: conceptual frameworks and evidence. Am Econ Rev 2015;105(5):183-6. https://doi.org/10.1257/aer.p20151012.

[29] Gerarden TD, Newell RG, Stavins RN. Assessing the energy-efficiency gap. J Econ Lit 2017;55(4):1486-525. https://doi.org/10.1257/jel.20161360.

[30] (GCC Statistical Center). Gccstat.Org, 2020 [gccstat.org].

[31] Abulibdeh A. Analysis of urban heat island characteristics and mitigation strategies for eight arid and semi-arid gulf region cities. Environ. Earth Sci. 2021;80(7). https://doi.org/10.1007/s12665-021-09540-7.

[32] Al-Saidi M. Instruments of energy subsidy reforms in Arab countries - the case of the Gulf Cooperation Council (GCC) countries. Energy Rep 2020;6: 68-73. https://doi.org/10.1016/j.egyr.2019.08.020.

[33] Al-Badi A, AlMubarak I. Growing energy demand in the GCC countries. Arab J. Basic Appl. Sci. Jan. 2019;26(1):488-96. https://doi.org/10.1080/ 25765299.2019.1687396.

[34] Meier A, Darwish M, Sabeeh S. Complexities of saving energy in Qatar. 2013.

[35] Al-Marri W, Al-Habaibeh A, Watkins M. An investigation into domestic energy consumption behaviour and public awareness of renewable energy in Qatar. Sustain. Cities Soc. 2018;41(January):639-46. https://doi.org/10.1016/ j.scs.2018.06.024.

[36] Abulibdeh A. Spatiotemporal analysis of water-electricity nexus in the context of the COVID-19 pandemic across six socioeconomic sectors in Doha City, Qatar. Appl. Energy 2021;304:117864. https://doi.org/10.1016 J.APENERGY.2021.117864.

[37] Gastli A, Charabi Y, Alammari RA, Al-Ali AM. "Correlation between climate data and maximum electricity demand in Qatar," in 2013 7th IEEE GCC Conference and Exhibition. GCC); 2013. p. 565-70. https://doi.org/10.1109/ IEEEGCC.2013.6705841.

[38] HollandPlusYou. Opportunities for Dutch business in the Gulf region -Water. https://www.netherlandsworldwide.nl/binaries/ennederlandwereldwijd/ documents/publications/2017/02/03/opportunities-fordutch-businesses-inthe-gulf-region-water-sector-lo_res.pdf/opportunities-for-dutchbusinessesin-the-gulf-region-water-sector-lo_res.pdf.

[39] Abulibdeh A. Modeling electricity consumption patterns during the COVID-19 pandemic across six socioeconomic sectors in the State of Qatar. Energy Strat Rev 2021;38(2021):100733.

[40] Ayoub N, Musharavati F, Pokharel S, Gabbar HA. Energy consumption and conservation practices in Qatar-a case study of a hotel building. Energy Build 2014;84:55-69. https://doi.org/10.1016/j.enbuild.2014.07.050.

[41] “'EnergyPlus Energy Simulation Software,' U.S. Department of Energy. http:/ apps1.eere.energy.gov/buildings/energyplus/. [Accessed 1 September 2012]. Accessed.

[42] Staff ICC. IgCC international green construction code: a comprehensive solution for highperformance buildingsvol. 2018. Incorporated: International Code Council; 2018

[43] “Typical Meteorological Year (TMY)." Nsrdb.Nrel.Gov.

[44] Breiman L. Classification and regression trees. Cytometry Sep. 1984;8(5): 534-5. https://doi.org/10.1002/cyto.990080516.

[45] van Buuren S, Groothuis-Oudshoorn K. Mice: multivariate imputation by chained equations in R. J Stat Software 2011;1(3). https://doi.org/10.18637/ jss.v045.i03.

[46] Breiman L. Bagging predictors. Mach Learn 1996;24(2):123-40. https:// doi.org/10.1023/A:1018054314350.

[47] Likas A, Vlassis N, Verbeek JJ. The global k-means clustering algorithm. Pattern Recogn 2003;36(2):451-61.

[48] Syakur MA, Khotimah BK, Rochman EMS, Satoto BD. Integration K-means clustering method and elbow method for identification of the best customer profile cluster. IOP Conf Ser Mater Sci Eng 2018;336:12017. https://doi.org/ 10.1088/1757-899x/336/1/012017.

[49] Ansi/ashrae, "ANSI/ASHRAE 55:2004 thermal environmental conditions for human occupancy. Ashrae 2004;2004:30. https://doi.org/10.1007/s11926011-0203-9.

[50] Sheather SJ. Density estimation. Stat Sci 2004:588-97.

[51] Rodgers M, Coit D, Felder F, Carlton A. Assessing the effects of power grid expansion on human health externalities. Socioecon. Plann. Sci. 2019;66: 92-104. https://doi.org/10.1016/j.seps.2018.07.011.

[52] Hui S. "Building energy efficiency standards in Hong Kong and mainland China", ACEEE summer study on energy efficiency in buildings. 2000. 